\section{A review of water and greenhouse gas impacts of unconventional natural gas development in the United States}

Douglas Arent, Jeffrey Logan and Jordan Macknick, Joint Institute for Strategic Energy Analysis, National Renewable Energy Laboratory, Golden, Colorado 80401, USA

William Boyd, Law Department, University of Colorado Boulder, Regent Administrative Center, Boulder, Colorado 80309-0552, USA

Kenneth Medlock III, Center for Energy Studies, Baker Institute, Rice University, Houston, Texas 77251-1892, USA

Francis O'Sullivan, MIT Energy Initiative, Massachusetts Institute of Technology, Cambridge, Massachusetts 02139, USA

Jae Edmonds and Leon Clarke, Joint Global Change Research Institute, Pacific Northwest National Laboratory, College Park, Maryland 20740, USA Hillard Huntington, Energy Modeling Forum, Department of Management Science and Engineering, Stanford University, Stanford, California 94305-6106, USA

Garvin Heath and Patricia Statwick, Joint Institute for Strategic Energy Analysis, National Renewable Energy Laboratory, Golden, Colorado 80401, USA

Morgan Bazilian, Columbia University, New York, New York 10027, USA

Address all correspondence to Douglas Arent at Doug.Arent@nrel.gov

(Received 12 July 2014; accepted 14 April 2015)

\title{
ABSTRACT
}

This paper reviews recent developments in the production and use of unconventional natural gas in the United States with a focus on water and greenhouse gas emission implications. If unconventional natural gas in the U.S. is produced responsibly, transported and distributed with little leakage, and incorporated into integrated energy systems that are designed for future resiliency, it could play a significant role in realizing a more sustainable energy future; however, the increased use of natural gas as a substitute for more carbon intensive fuels will alone not substantially alter world carbon dioxide concentration projections.

This paper reviews recent developments in the production and use of unconventional natural gas in the United States with a focus on environmental impacts. Specifically, we focus on water management and greenhouse gas emission implications. If unconventional natural gas in the United States is produced responsibly, transported and distributed with little leakage, and incorporated into integrated energy systems that are designed for future resiliency, it could play a significant role in realizing a more sustainable energy future. The cutting-edge of industry water management practices gives a picture of how this transition is unfolding, although much opportunity remains to minimize water use and related environmental impacts. The role of natural gas to mitigate climate forcing is less clear. While natural gas has low $\mathrm{CO}_{2}$ emissions upon direct use, methane leakage and long term climate effects lead to the conclusion that increased use of natural gas as a substitute for more carbon intensive fuels will not substantially alter world carbon dioxide concentration projections, and that other zero or low carbon energy sources will be needed to limit GHG concentrations. We conclude with some possible avenues for further work.

Keywords: unconventional natural gas, natural gas and environmental impacts, natural gas in energy scenarios, unconventional natural gas and water 


\section{DISCUSSION POINTS}

- Multiple studies have addressed responsible development practices and the importance of reducing associated emissions in relation to climate mitigation, as well as local air pollution. The responsible development and use of unconventional natural gas is compounded by a large set of risks ranging from water, to land use, the methane emissions, technology crowding out and lock-in, and social acceptance.

- If unconventional natural gas is produced responsibly, transported and distributed with little leakage, and incorporated into integrated energy systems that are designed for future resiliency, it can likely play a significant role in realizing a more sustainable energy future.

- Natural gas can help reduce greenhouse gas (GHG) emissions, but in the absence of targeted climate policy measures, it will not substantially alter the trajectory of global GHG concentrations.

- Natural gas can be a complement to other low carbon technologies, particularly renewables, and can help reduce the potential costs and challenges for large scale CCS implementation compared to coal based solutions.

\section{Recent natural gas developments in the United States}

This section briefly considers the scale of the U.S. unconventional resource before turning to issues of environmental impacts and trade-offs.

This paper reviews aspects of the natural gas "revolution" in the United States as well as its impacts on the environment and trade-offs with particular environmental objectives. In doing so, it focuses on recent developments in unconventional gas primarily from shale plays in the continental United States (see Fig. 1). This revolution was not predicted temporally or in scale by almost any analyst in industry or academia. *

Techniques for horizontal drilling combined with hydraulic fracturing (fracking) for extracting shale gas were improved in the late 1990s and use of the technology spread quickly, resulting in increasing shale gas output as well as estimates of technically recoverable resources. The relatively rapid spread of fracking has also raised environmental and social concerns that the regulatory community and other stakeholders are grappling with.

Prior to 2003, most of the widely accepted assessments of technically and economically recoverable shale resources considered them to be fairly minimal. Over the last 10 years, however, the state of knowledge regarding the amount of shale gas that is technically recoverable has changed rapidly. ${ }^{2}$ Assessments of shale gas resources were initially focused on shale plays in North America, largely because that is where commercial interest in the resource first revealed itself. A simple chronology of estimates of North American shale gas through 2011 illustrates the change:

- 2003, the National Petroleum Council ${ }^{3}$ - 38 trillion cubic feet (tcf).
- 2005, the Energy Information Agency (EIA) - 140 tcf.

- 2008, Navigant Consulting, Inc. ${ }^{4}-640$ tcf.

- 2009, the Potential Gas Committee ${ }^{5}$ - over 680 tcf.

- 2011, Advanced Resources International (ARI) ${ }^{1}-1930$ tcf.

Note that although each assessment cited in this highlight chronology is from an independent source, the estimates have increased over time as more drilling has occurred, allowing better characterization of the resource, and as operators have developed deeper knowledge about the acreage under development-a "learning-by-doing" process that is still occurring in shale plays everywhere. Moreover, the shift in the generally accepted assessment of recoverable shale resources has left producers, consumers, and governments all grappling with the implications for markets, trade, geopolitics, and the environment.

Change in the generally accepted assessment of shale resources has continued beyond 2011. Table 1 provides a snapshot of the rapid, very recent change in assessments of technically recoverable shale gas and oil resources globally according to studies commissioned by the EIA. Although assessments are fraught with uncertainty, it is useful to recognize the potential enormity of the resources. These resources highlight the scale of the environmental pressures that may manifest. It is also important to note that the assessments referenced in Table 1 are either incomplete or simply do not include several regionsRussia and the Middle East, for example-where there is a history of considerable natural gas and crude oil production from conventional resource plays. To the extent that the source rocks for those conventional plays turn out to be productive shales, the assessed volumes in Table 1 are likely to be low, which will result in further upward refinements of the global assessment. Finally, it is important to point out that commercial viability of shale resources is distinct from technical viability. One can think of commercially recoverable resources as a subset of technically recoverable resources, as the former considers both technology and economic factors whereas the latter only considers technology. Indeed, there may be commercial reasons why much of the resource that is assessed to be technically recoverable will never actually be developed. Moreover, many of the factors that shape commercial viability are above-ground and therefore may render some of the assessed resource unattractive as development opportunities. ${ }^{6}$ In any case, the commercially viable resources are the relevant resources for this discussion as they will be the primary source of production activity going forward.

To date, the bulk of global experience from upstream exploration and production with the shale gas resource has occurred in a relatively few geographic locations in the United States. However, the concerns over environmental impacts of shale development, as well as potential implications for climate change, are not restricted to the United States. Other jurisdictions with as-yet untapped resources are closely monitoring technical developments as well as examining a variety of issues ranging from how environmental concerns will be addressed, to how the social license to operate can be secured and maintained. ${ }^{8-10}$ For example, the European Parliament study ${ }^{11}$ of health and 


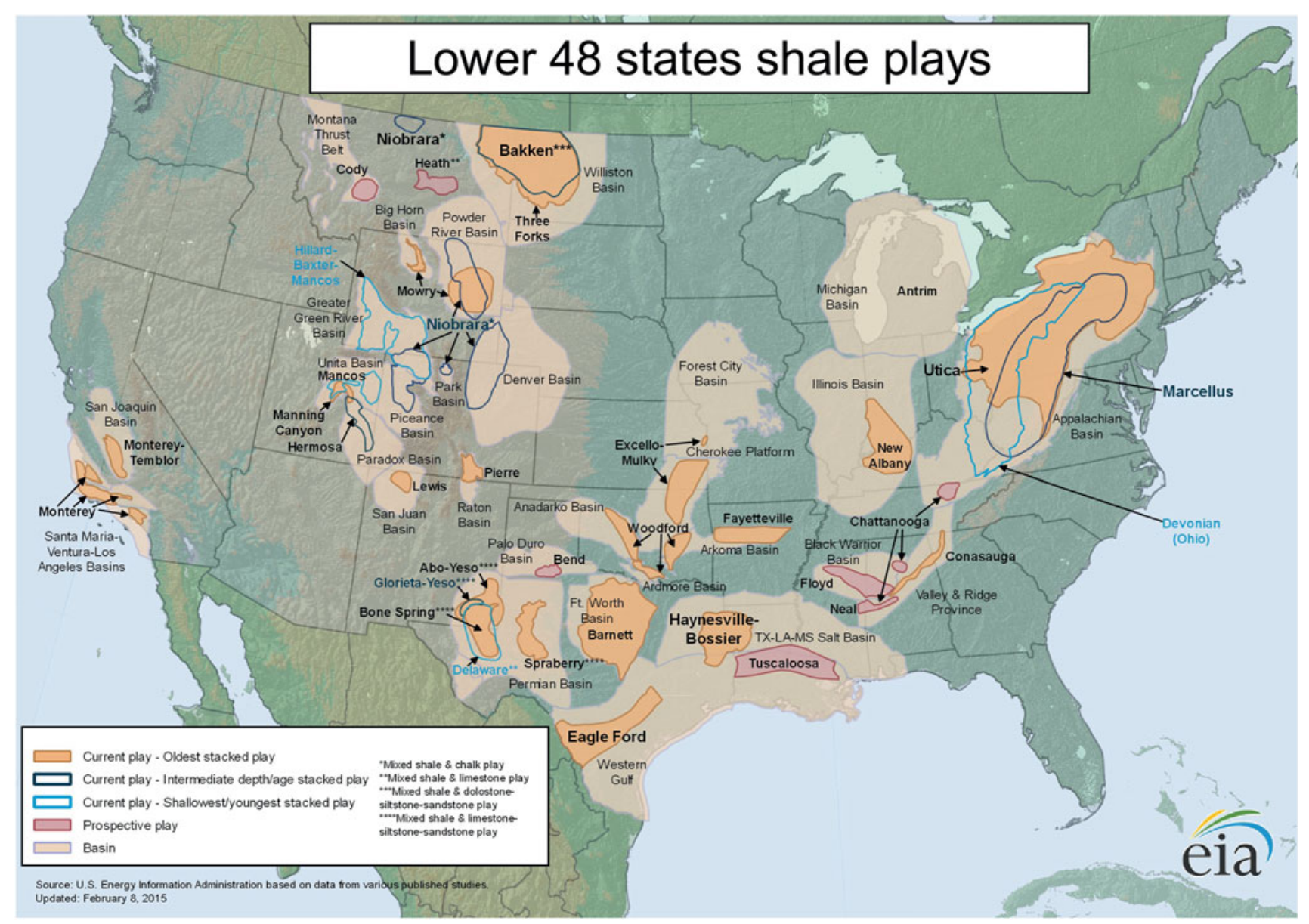

Figure 1. U.S. lower 48 shale plays. ${ }^{1}$

Table 1. Global shale oil and gas resources.?

\begin{tabular}{l|c|c} 
& 2011 Report & 2013 Report \\
\hline Number of countries & 32 & 41 \\
\hline Number of basins & 48 & 95 \\
\hline Number of formations & 69 & 137 \\
\hline $\begin{array}{l}\text { Technically recoverable } \\
\text { resources, including U.S. }\end{array}$ & $\ldots$ & $\ldots$ \\
\hline $\begin{array}{l}\text { Shale gas (trillion cubic feet) } \\
\text { Shale/tight oil (billion barrels) }\end{array}$ & 6622 & 7299 \\
\hline
\end{tabular}

Note: The 2011 report did not include shale oil; however, the Annual Energy Outlook 2011 did (for only the U.S.) and is included here for completeness. environmental impacts considered a wide variety of issues, including impacts on landscape, air pollution, GHG emissions, surface and ground water, seismicity, and chemicals and radioactivity as well as long-term ecological impacts and resource consumption.

Still, uncertainty remains in understanding the full environmental impacts of shale gas development, particularly as practices continue to evolve rapidly. As Wood et al. note, "There is a real paucity of information on which to base an analysis of how shale gas could impact GHG emissions and what environmental and health impacts its extraction may have." 12 We focus here on water management-related issues and GHG emission implications: water withdrawal and use, water "produced" by well operations, and water disposal; and methane and GHG life cycle emissions. Within our focus areas, there is a rapidly growing literature; however, a gap exists between academic research and industry best practice, particularly for water-related issues. We also recognize that a wider set of issues associated with shale development exists-from economics and security, to drilling efficiency and safety, to resource estimates, infrastructure development, public health, and demand projections-but these already are covered elsewhere. ${ }^{13-30}$ For example, Krupnick et al. 
dedicate a chapter of their report to environmental issues, including water quantity and quality, air quality, habitat, human health, ecosystems and species, cumulative and scale, and valuation and messaging. ${ }^{31}$

Section "State of knowledge and emerging trends in water and GHG emissions" takes a closer look at the impacts of unconventional shale gas development on water and GHG emissions. Section "Implications for pathways toward a sustainable energy future" considers natural gas as part of a pathway to a sustainable energy future, and Section "Some areas for further research" concludes.

\section{State of knowledge and emerging trends in water and GHG emissions}

This section reviews the academic and gray literature in key areas of environmental impact related to unconventional gas, focusing on water use and produced water and methane emissions, and the U.S. regulatory and legislative landscape governing these areas.

Environmental stewardship is central to the long-term success of the natural gas industry. ${ }^{32-39}$ A general framework of the environmental risk factors of unconventional natural gas development can be found in Fig. 2. This framework includes land disturbances, seismicity, local air quality, and community impacts more generally, as well as the two main areas of our focus: water issues and GHG emissions.

Increasingly, stakeholders representing a broad cross-section of society, including many local and regional groups, are seeking greater transparency of and more involvement in shale gas development decisions. ${ }^{31,42}$ Accordingly, regulation of the

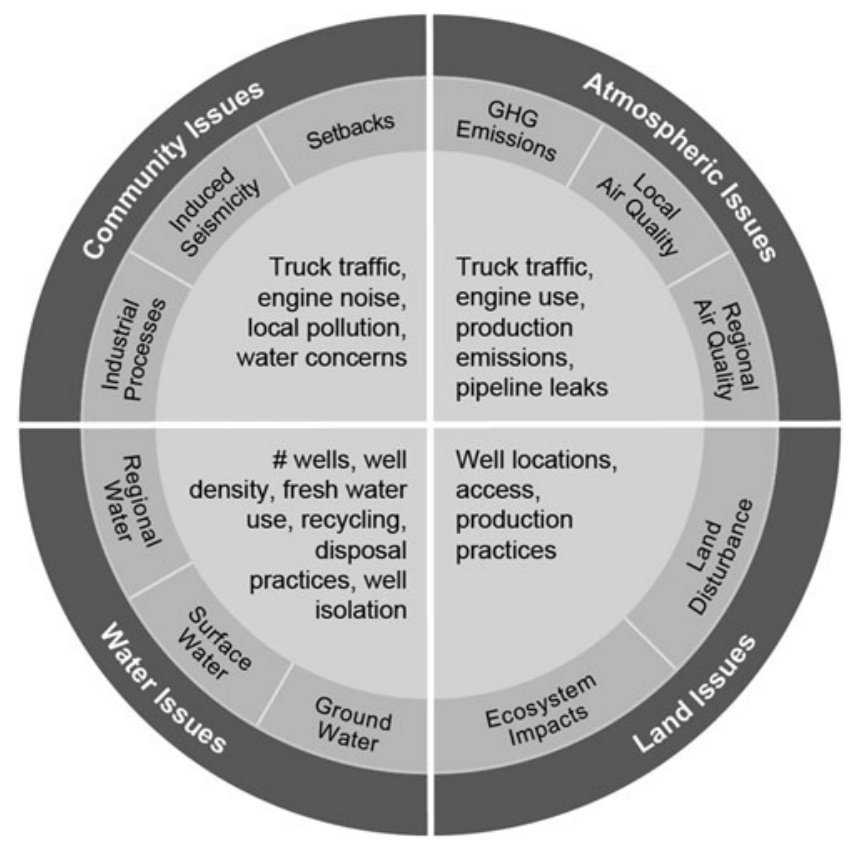

Figure 2. Environmental risk factors for shale development. ${ }^{40-41}$ environmental impacts of shale gas development has been increasing at all levels of governance. ${ }^{42}$ This has resulted in local and state-wide ballot initiatives, increased legislative activity, new regulations, and litigation. ${ }^{42-43}$

The broader legal and regulatory framework governing the various environmental impacts of unconventional natural gas development in the United States is complex, dynamic, and multilayered. ${ }^{31,42}$ States continue to be the most active regulatory actors, and the diversity of state approaches provides important opportunities for learning and innovation regarding best practices, substantive rules, and multistakeholder processes. ${ }^{31,42,44-45}$ The federal government has sole responsibility for regulating oil and gas development on federal lands, and the Bureau of Land Management (BLM) has recently issued a new proposed rule regulating hydraulic fracturing on these lands. ${ }^{46}$ EPA has important ongoing responsibilities associated with oil and gas production, particularly, with respect to impacts on air and water quality. The President has also taken a series of executive actions intended to address some of the environmental impacts of shale gas development, including a 2012 Executive Order: Supporting Safe and Responsible Development of Unconventional Natural Gas Resources ${ }^{47}$ and the President's Climate Action Plan, ${ }^{48}$ which specifically identifies methane emissions from natural gas production and use as a priority and establishes an Interagency Methane Strategy to assess current emission data, address data gaps, identify technologies and best practices for reducing emissions, and identify existing authorities and incentive-based approaches to reduce methane emissions.

Conflicts regarding environmental impacts have also emerged in certain areas of the country, leading to restrictions and moratoria on drilling by state, county, and municipal governments and raising questions about the industry's continued social license to operate in specific jurisdictions. ${ }^{42,49}$ Efforts by local governments to exert more control over shale gas development have resulted in litigation in several states as well as new legislation and regulations intended to resolve some of these conflicts. ${ }^{42-43}$

Recent public opinion surveys reveal a general appreciation for the economic benefits of shale gas development but continued concerns about potential health and environmental impacts. In a survey of Pennsylvania and Michigan residents conducted in 2012, a large majority in both states recognized the economic importance of hydraulic fracturing to their states, while a more modest majority in both states supported a moratorium on shale gas extraction until there is further understanding of its risks. ${ }^{50}$ Additional insights into public opinion were found in Texas and Pennsylvania, indicating general support, but also high degree of concern for environmental protection. ${ }^{51}$

We now turn to the consideration of water issues and GHG emissions in somewhat more detail.

\section{Water}

A comprehensive and objective understanding of water resource risks and risk management in the production and processing of natural gas is vital to sound decision-making. With many areas of the U.S. experiencing drought conditions from severe 
to exceptional ${ }^{\dagger}$, water resources are already under stress. Fresh water is a valuable resource, and many aquifers are overstressed by both drought and competition for domestic, agricultural, and industrial water needs, including water needed for hydraulic fracturing operations. Groundwater depletion-a situation in which water is withdrawn from aquifers faster than it can be replenished-is occurring in many areas where there are shale plays. Depletion not only reduces the quantity of available water, it can also result in an overall deterioration of water quality. ${ }^{42}$

All phases of shale gas development have the potential to affect either the quantity or quality of local water resources. ${ }^{53-54}$ We focus on water management practices that can lead to environmental impacts versus reviewing the specific environmental impacts that may arise as a consequence of fracking. EPA describes potential water impacts of hydraulic fracturing as occurring during five stages: water acquisition, chemical mixing, well injection, flowback and produced water, and wastewater treatment and waste disposal.* Water quantity concerns are primarily associated with the water acquisition phase, as large volumes of water are required for hydraulic fracturing operations over a short period of time. Water quality concerns are mainly associated with the remaining four phases. Figure 3 illustrates that the variety of water quantity and quality risks shale gas development could pose for local water resources.
Quantity related risks depend on the number of wells drilled, water use per well, amount of recycling or nonpotable water use that occurs to offset freshwater demands, and local water availability. Water use per well is dependent on well characteristics such as depth, horizontal drilling distance, and local geological conditions. As shale gas development continues to grow rapidly across the United States, the total demand for water used during site operations is projected to increase in many areas. ${ }^{55}$ Drilling and fracking operations involved in shale gas development require millions of gallons of water per well that must be acquired and transported to sites to fracture the shale formations. ${ }^{42,56-57}$ These requirements bring shale gas development into direct competition with domestic and agricultural uses of fresh water. Figure 4 provides a sense of the scale of the water required per fractured well in various plays for a particular year-along with the fairly large levels of uncertainty or error in the estimates.

It is worth putting in perspective the relative amount of water used during natural gas production, whether conventional or unconventional, compared to what is used during the generation of electricity by various types of natural gas power plants, as well as power plants using other fuels. Figure 5 shows that the water consumption for natural gas production is a

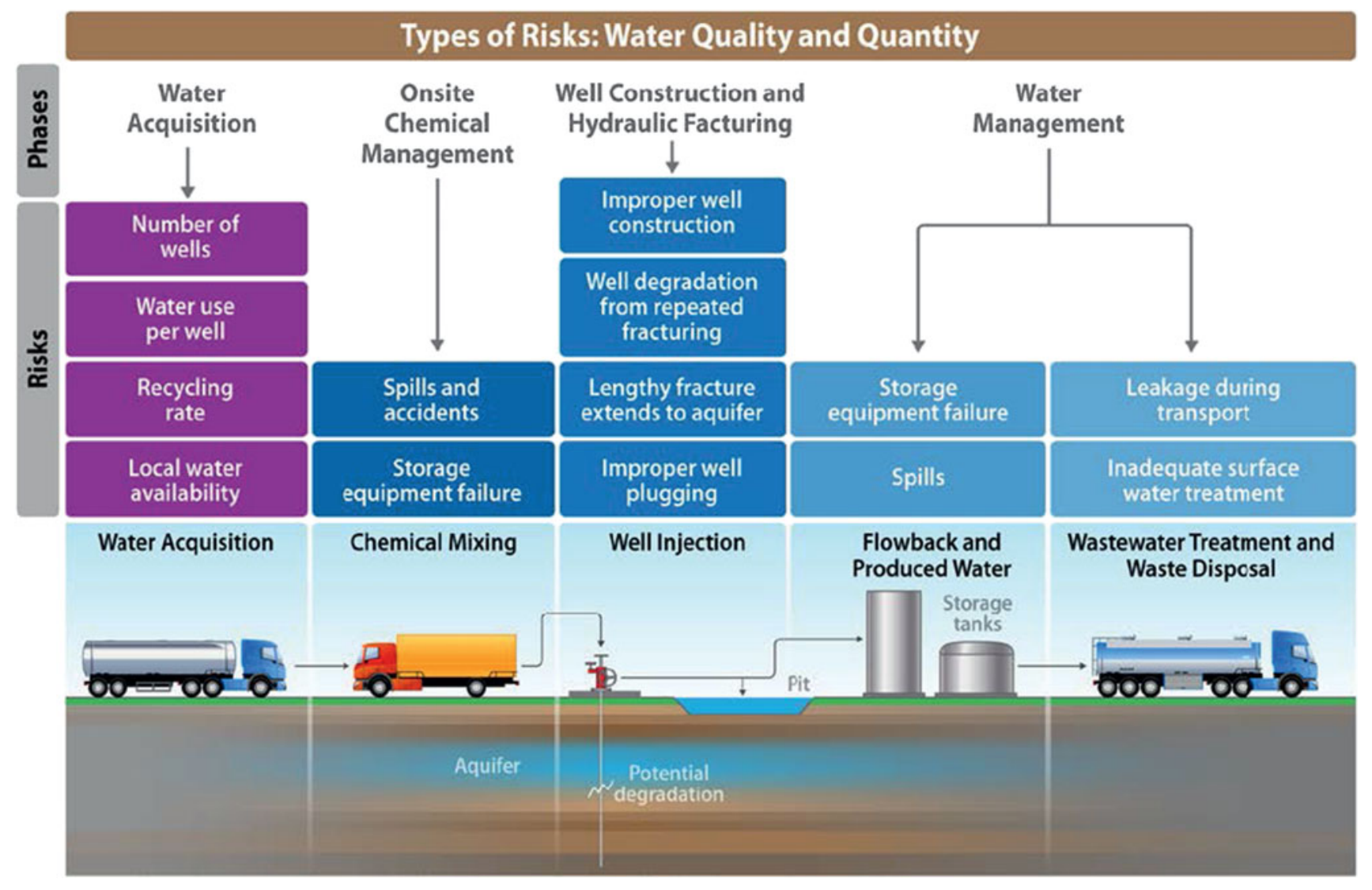

Figure 3. Overview of risks to water resources throughout various phases of shale gas development. ${ }^{42}$ 


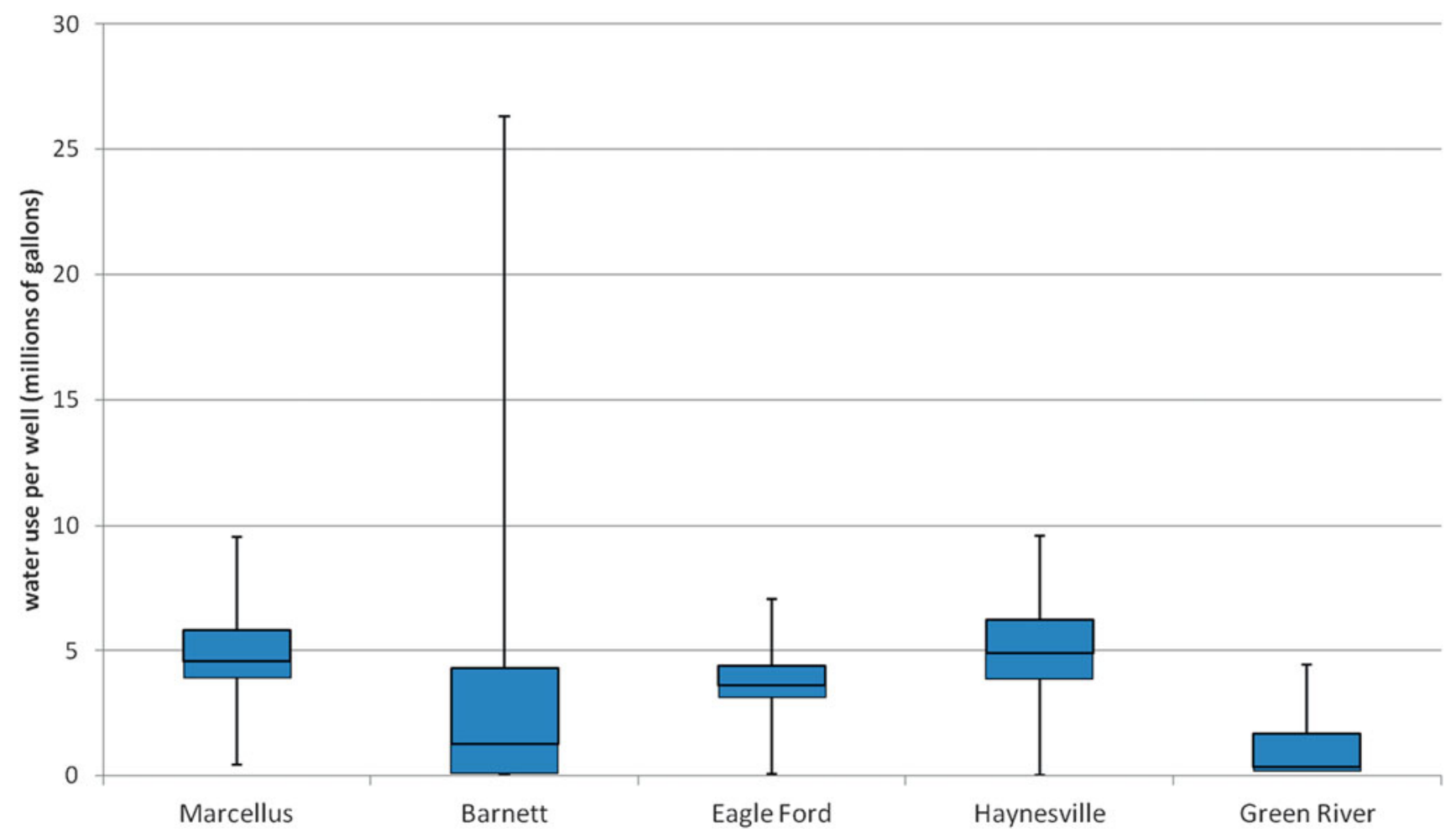

Figure 4. Water use (and error bars) per fracture on selected wells in the year 2011. Note: Low and high error bars represent minimum and maximum reported water usage per well, respectively. Upper and lower ends of boxes represent 75th and 25th percentile, respectively. Horizontal lines in boxes represent medians. ${ }^{42}$

relatively small percentage of total water consumption for most types of natural gas power plant operations. This is due to the large water requirements associated with traditional power plant cooling technologies. Water consumption differences associated

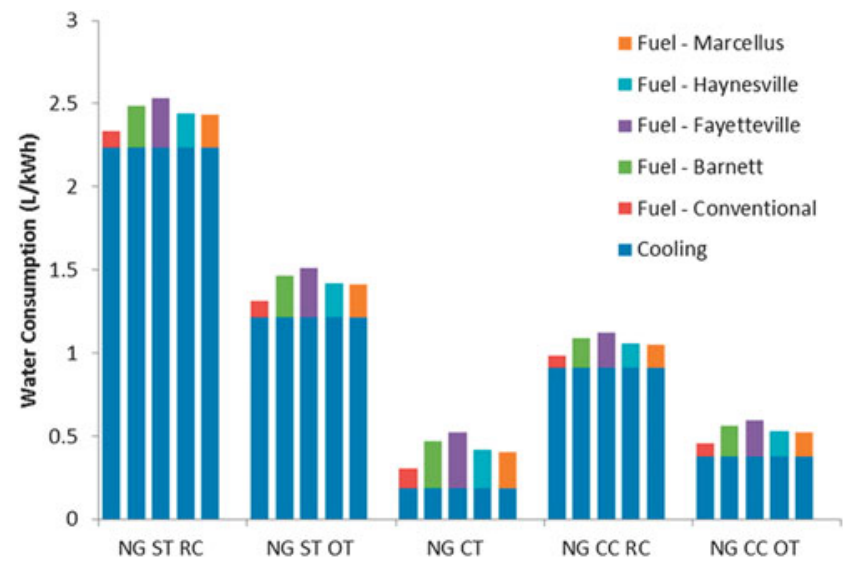

Figure 5. Water consumption rates in liters per kilowatt-hour (L/kWh) for the life cycle stages of natural gas generation. ${ }^{58}$ Note: NGST is natural gas steam turbine, NGCT is natural gas combustion turbine, NGCC is natural gas combined-cycle, $\mathrm{RC}$ is recirculating cooling, and $\mathrm{OT}$ is once-through cooling. with fuel production from different sources are small relative to the differences between fuel production and power plant cooling water requirements, with the exception of natural gas combustion turbines (NGCT), regardless of prime mover type and cooling system type. Figure 6 compares life cycle water consumption among different electricity generating technologies and fuel types. Modern natural gas power plants generally consume less water than other thermal electricity technologies, and only require more water on a life cycle basis than wind and photovoltaic technologies, when normalized for electricity output (Fig. 6).

It should be noted that life cycle water use rates that are amortized to total lifetime energy output cannot capture the temporal nature of natural gas water usage. For unconventional oil and gas development, all the water required for well production occurs over a small number of days, whereas the water required for coal or uranium mining and processing occurs throughout the lifetime of the mine. This temporal asymmetry in when water usage occurs can lead to localized water stresses resulting from oil and gas development that are not captured through these static metrics.

Quality-related risks depend on onsite construction techniques, onsite chemical management practices, and wastewater management practices, as well as the geochemical composition of the formations being developed. During operations, there are millions of gallons of wastewater that must be stored, 


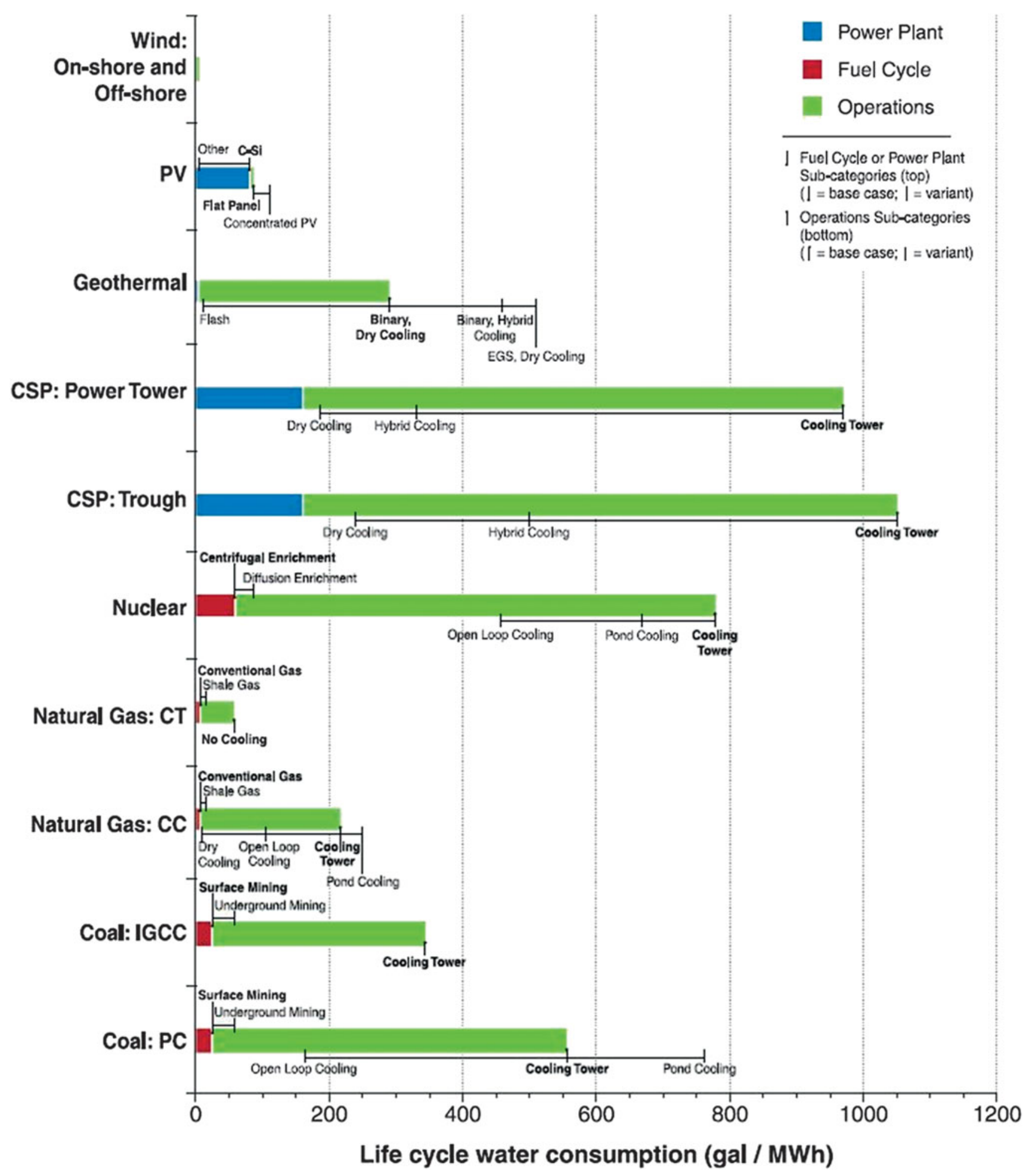

Figure 6. Water consumption rates in gallons/megawatt-hour (MWh) for the life cycle stages of electricity generating technologies. ${ }^{59}$

transported, treated, and/or disposed of. Risks may vary for any given shale gas development site. In many cases, risks to water resources extend beyond the location of the well being drilled, depending on the source location of the water and where wastewater is treated.
Vengosh et al. (2014) identified the most likely pathways for water quality degradation: groundwater contamination due to stray gas, fracking water, and/or formation water from leaking wells; surface water contamination from spills, leaks, and poor wastewater treatment practices; toxic elements that accumulate 
in the soil and eventually make their way into ground and surface water; and degradation through overextraction. ${ }^{60}$ These pathways, and corresponding levels of contamination, have been confirmed by several studies: Osborn et al. (2011) identified higher levels of thermogenic methane (i.e., methane from deep sources, consistent with shale gas, as opposed to biogenically produced surface methane) in shallow water wells closer to areas of active shale gas development. ${ }^{61}$ At the same time, no evidence of contamination from fracking fluids or deep brines was found. The most likely mechanism for groundwater contamination was identified as leaky gas-well casings. ${ }^{61-62}$ Using noble gases as a tracer, Darrah et al. (2014) were able to confirm that likely sources of leaks include faulty well casings; poorly cemented well annuli (the void that directs drilling fluid and drill cuttings back up to the surface); and improperly abandoned gas wells. ${ }^{63}$ Surface water can be impacted as well: Olmstead et al. (2013) found that shale gas well construction negatively affects downstream water quality as measured by total suspended solids; and that the offsite treatment of shale gas waste in permitted treatment plants raises downstream concentrations of chloride, a component of well wastewater. ${ }^{64}$

Currently, best management practices (BMPs) to mitigate quantity or quality related risks have not been established by industry and stakeholder groups. Efforts have been made to encourage shale gas developers to develop industry standards to protect water resources. In its 2011 report identifying measures to reduce the environmental impact of shale gas production, the U.S. Department of Energy's Secretary of Energy Advisory Board (SEAB) identified four recommendations for the protection of water quality. Recognizing that different approaches to implementation would be required in different regions, the SEAB suggested that the responsibility for implementing these four recommendations should be at the state level, with state regulators and industry working together to develop a plan (Table 2). ${ }^{65}$

Various attempts have been made to define BMPs for water management. ${ }^{10,66-70}$ For example, prior studies have noted that quantity-related risks can be mitigated by recycling wastewaters from the fracking process for reuse in new wells, or by using other, nonfresh sources of water. Recycling of flowback water for reuse in fracking operations is increasingly being used in the industry, motivated by a variety of factors in different locations, such as economic, regulatory, freshwater availability, or social license to operate. Figure 7 shows the example of water treatment methods by proportion of water volumes treated in different manners for a series of years in Pennsylvania, where reuse jumped from $10 \%$ of wastewater volume to $80 \%$ in just three years, on a 4 -fold increase in wastewater volume over the same period. This was due in part to regulatory changes in Pennsylvania, and the expense associated with transporting wastewater for disposal to the nearest treatment facilities in Ohio. ${ }^{71}$ In other locations, low-cost freshwater acquisitions as well as relatively low-cost underground injection wastewater disposal opportunities have limited the widespread adoption of recycling activities.

Quality-related risks can potentially be mitigated through a variety of techniques that address the possible water contamination pathways of development activities. Water-quality related risks pose additional challenges over water quantity-related risks because there are multiple processes along the development chain involving multiple operating companies that could lead to water contamination. Examples of mitigation techniques for contamination pathways include:

- Proper well construction techniques to address faulty well casings and poorly cemented well annuli.

- Using a closed-loop drilling system, which can minimize opportunities for spills.

- Eliminating flowback water mixing with freshwater in open impoundments through the use of separate water tanks, which reduces spills and avoids water leaking through impoundments.

- Using protective liners for pits and tanks to prevent water seepage.

- Minimizing the use of toxic chemical additives in case there is an uncontained spill.

- Proper well abandonment practices.

Table 2. Selected recommendations from the Secretary of Energy Advisory Board. 65-66

\begin{tabular}{l|l|l}
\multicolumn{2}{c}{ Rec.\# } & \multicolumn{2}{c}{ Recommendation } \\
\hline 8 & $\begin{array}{c}\text { Measure and publicly report the composition of water stocks } \\
\text { and flow throughout the fracturing and cleanup process. }\end{array}$ & $\begin{array}{c}\text { Await EPA's study underway on the impacts of hydraulic } \\
\text { fracturing on drinking water resources. States should } \\
\text { also determine a way forward to measure and record } \\
\text { data from flow back operations as many issues will be } \\
\text { local issues. }\end{array}$ \\
\hline 10 & $\begin{array}{l}\text { Manifest all transfers of water among different locations. } \\
\text { especially casing, cementing, and pressure management. }\end{array}$ & $\begin{array}{c}\text { Widely recognized as a key practice by companies and } \\
\text { regulators but no indication of a special initiative on } \\
\text { field measurement and reporting. }\end{array}$ \\
\hline 12 & Adopt requirements for background water quality measurements. & $\begin{array}{l}\text { The value of background measurements is recognized. } \\
\text { Jurisdiction for access to private wells differs widely. }\end{array}$ \\
\hline
\end{tabular}

8 - MRS ENERGY \& SUSTAINABILITY // VOLUME 2 // e4 // www.mrs.org/energy-sustainability-journal 


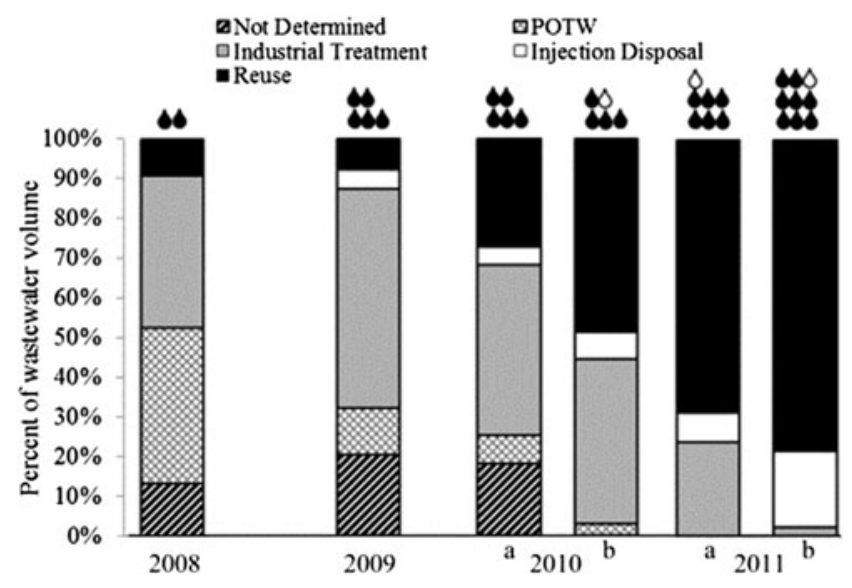

Figure 7. Water disposal volumes and methods in Pennsylvania by reporting period from 2008-2011. ${ }^{71}$ For the years 2008 and 2009, reporting was annual. In the years 2010 and 2011, data were reported for roughly the first and second half of each year, denoted by "a" and "b," respectively. POTW represents publicly operated treatment works. Water drops indicate total wastewater volumes: shaded drops $=200,000 \mathrm{~m}^{3}$; open drops $=100,000 \mathrm{~m}^{3}$.

Although these opportunities describe generally how to prevent contamination risks, these efforts can be implemented in a variety of ways depending on company common practices, state-level requirements, and region-specific conditions. $\$$

In the absence of specific BMPs, federal and state regulation is an alternative, though one not preferred by the industry. Currently, there is little consistency in regulations from one state to the next regarding water and wastewater management practices associated with unconventional oil and gas development. This is due, in part, to the heterogeneity in multiple dimensions found within each shale play-including geology, well performance, and a number of above-ground local issues-thus requiring diverse approaches. Geological and geochemical differences associated with each shale play indicate that some practices may be effective in some plays but not others. For example, some plays might have geological conditions that support ample disposal wells for wastewater disposal, whereas others might have different geological conditions that make underground injection in the play unfeasible, so that wastewater must be transported out of the play or otherwise treated and reused.

The regulatory frameworks governing risks to water quantity and quality are dynamic and multilayered. Regulation of water withdrawals is primarily a matter of state and local law (other than on federal lands), and the legal framework governing water rights differs from state to state, although there is some consistency along regional lines. ${ }^{67}$ There is a trend among states toward requiring operators to identify the sources of water used and to report the amount of water used in hydraulic fracturing. In addition, more states are providing incentives to promote reuse of water used in hydraulic fracturing such as by recycling flowback waters or production fluids. ${ }^{42}$
With respect to risks to water quality, states have primary responsibility. The process of hydraulic fracturing, other than when diesel fuel is used, is expressly excluded from federal regulation under the Safe Drinking Water Act's Underground Injection Control program. States have therefore taken the lead in regulating well construction and other aspects of hydraulic fracturing to mitigate potential risks to water quality. ${ }^{42,44}$ Working across state governments, many partnerships and organizations are active in addressing water management regulatory issues. For example, according to the Secretary of Energy Advisory Board (SEAB), the State Review of Oil and Natural Gas Environmental Regulations (STRONGER) and the Ground Water Protection Council (GWPG) are two existing organizations that work to share information to improve the quality of regulatory policy and practice in the states. The budgets for these organizations are small and merit public support. Previously, federal agencies (DOE and EPA) provided funding for STRONGER and GWPG, but federal funding is currently not provided. To maintain credibility and to ensure their ability to set their own agenda, these organizations cannot rely exclusively on funding provided by companies of the regulated industry. ${ }^{65-66}$

EPA does have broad authority to regulate direct and indirect discharges of wastewater from point sources under the Clean Water Act and the injection of produced water into underground injection wells for disposal under the Safe Drinking Water Act. In response to a congressional request, EPA has also initiated a multiyear study to understand the potential impacts of hydraulic fracturing on drinking water resources. ${ }^{57}$ The study has been designed to cover the full life cycle of water in hydraulic fracturing and is scheduled for release in draft form in late 2014. When completed, the study should provide a more comprehensive understanding of the relationship between hydraulic fracturing and drinking water resources.

Once this relationship is understood, a first step in developing BMPs for reducing risks to water resources in shale gas development is to evaluate the efficacy and technological potential of various water risk management practices. Further examination of BMPs could assist developers in evaluating important water management questions-such as whether installing protective liners at pad sites or reducing use of certain chemical additives would have a greater impact on reducing risks to water resources in specific regions. Such analysis of BMPs could also provide greater insight into opportunities and risks for regulators, policymakers, and other stakeholders, as well as GHG emissions. ${ }^{72}$ In some cases, recycling wastewaters can be more expensive than other waste management options as it involves energy for treatment along with costs associated with storing water, transport of water, and transport and disposal of the solid wastes removed from the treated water. Further research is needed to better understand these trade-offs.

An additional area of needed research is to evaluate the extent to which certain water risk management practices are applicable or effective across multiple types of formations. As noted above, some practices might be less appropriate or cost-effective than others under certain geochemical conditions. For example, using recycled flowback or produced water for 
secondary fracking operations may be a challenge in certain areas because this water may contain high concentrations of undesirable impurities.

Comprehensive analyses of water risks are hindered by a lack of reliable, publicly available data. Data are not publicly available for many regions for total water withdrawals, total wells drilled, water recycling techniques, wastewater management, and other management practices. There are no international, national, or state-level disclosure initiatives to track or evaluate the success of BMP implementation. For example, it is difficult to determine how many operators are currently using (and with what success) the widely discussed BMP to use closedloop drilling practices because operators are not required to report this information. These data would assist in developing appropriately flexible and adaptive BMPs. In the absence of such reporting, data collection efforts would likely require close collaboration with multiple industry partners operating in a variety of locations.

Based on research by JISEA (2012), ${ }^{42}$ the following BMPs were identified as being important for minimizing risks related to water quality and quantity:

- Measure and publicly report the composition of water stocks and flow throughout the fracturing and cleanup process.

- Adopt standardized requirements for baseline water quality testing.

- Use a closed-loop drilling system.

- Fully disclose hydraulic fracturing fluid additives, with greater clarity on trade secret exemptions. * *

- Eliminate flowback water mixing with fresh water in open impoundments.

- Use protective liners at pad sites.

- Minimize use of chemical additives and promote the development and use of more environmentally benign alternatives.

- Optimize recycling of flowback water.

A criticism of best practice studies to date has been the lack of data that supports the efficacy of these practices for reducing risk and the lack of accountability. ${ }^{73-74}$ The list presented above is not described by any of the references with data showing how effective these practices are at producing the expected benefits. Equally important is that no economic analyses are provided that allow business decisions to be made assuming several options are available (including doing nothing). In addition to the lack of characterization of the recommended practices, it is not clear which of these will provide the greatest benefit for risk management. For example, research is needed to determine the benefit of protective liners at pad sites. Would it be better to concentrate on recycling flowback water or installing liners? Assuming finite resources, some sort of methodology for associating practices with risks is needed.

Because BMPs are not legally binding, the potential for lack of accountability is a concern. The publicly available reports tend to use words such as "encourage," "strive," and "should consider" regarding these practices leading to the possible conclusion that these are the "right" things to do and they should be implemented in one form for all to follow, yet there is no legal requirement to do so. When properly applied, "best practices" are most often adopted with thorough and detailed economic and efficacy data, allowing stakeholders including industry, regulators, researchers, environmental groups, and the public to understand what practices are currently in use, how effective they are at reducing the risk of water impacts, and where improvements are needed. When BMPs are not properly applied-or in the case of the shale gas industry, are unclear and inconsistently applied-stakeholders are likely to hear calls for binding regulation.

With little success, attempts were made in the preparation of this publication to collect data regarding the character and use of the recommended practices from industry and public databases including FracFocus (www.fracfocus.org). Disclosure of fracturing fluid chemicals on fracfocus.org is now in place in Colorado, Wyoming, and Texas and is being considered in several other states. The specific reporting requirements of proposed legislation with regard to what types of chemicals would have to be disclosed; where the disclosure would be published; whether volumes of chemicals would be required; and how trade secret chemicals would be addressed can differ greatly from state to state. ${ }^{44,75}$ While initiatives like FracFocus are highly valuable for improving transparency and accessibility of data sets, much more data by many more players need to be disclosed for the data to be useful. For example, important recommended practices such as closed-loop drilling and baseline water quality testing do not have disclosure requirements and therefore are not accessible from public databases. Industry collaboration will be needed to gather much of the data related to the current use of recommended practice.

Although much work is being done to identify sources and pathways of water resource contamination, our current understanding of water-related risks and risk mitigation techniques in shale gas developments leaves important questions unanswered. A full characterization of the sources and the mechanisms of contamination is needed, followed by an examination of effective practices and procedures to eliminate or mitigate the risks of contamination of water resources. Additional analysis is needed to quantify the costs and benefits of shale gas development in light of the identified risks and the costs of mitigation, ${ }^{64}$ as well as for remediation of contamination that has already occurred. This type of analysis will be critical to establishing those BMPs and government regulations, where needed, which will ensure that shale gas can be responsibly and sustainably produced.

In summary, water related science and analysis indicates the following at this time:

- All phases of shale gas development have the potential to affect either the quantity or quality of local water resources. ${ }^{53-54}$

- Water resources in many areas where shale plays exist are already experiencing groundwater depletion due to 
drought conditions and consumption exceeding recharge rates by domestic, agricultural, and industrial sectors. ${ }^{52}$

- Water resources in many areas where shale plays exist are already experiencing water resource contamination tied to hydraulic fracturing activities. ${ }^{61}$

- Industry and stakeholder groups have established no standard set of BMPs for managing water use or water quality; further, there is little consistency in regulations from one state to the next regarding water and wastewater management practices associated with unconventional oil and gas development.

- A full characterization of the sources and the mechanisms of actual and potential contamination is needed, followed by an examination of practices and procedures to eliminate or mitigate the risks of depletion and contamination of water resources.

- Based on findings, producers might consider developing and adopting cost-effective, appropriately flexible, and adaptive BMPs or a set of strong principles. Accountability reporting, measurement, and verification standards will assure adherence to generally recognized BMPs and the principles to safeguard water supplies and water quality, adapted to their region and their specific situations.

\section{Greenhouse gas emissions}

A comprehensive and objective understanding of GHG emissions from the production, processing, and transmission of natural gas is vital to understanding the potential role of natural gas in mitigating climate change. The GHG impacts of gas-particularly in comparison with coal as well as diesel and gasoline for many markets-affect decisions on future power sector developments, industrial practices, regulatory policy, and sectoral applications. Figure 8 illustrates such a comparative life cycle assessment (LCA) for power generation after methodological harmonization. The current understanding of GHG emissions from natural gas systems leaves important questions unanswered and has resulted in considerable technical debate. ${ }^{76}$ Scientific studies fall into two categories: bottomup assessments estimate GHG emissions from natural gas systems based on component-level emission profiles and counts; top-down assessments use measurements of methane in the atmosphere, and then estimate a portion attributable to natural gas systems. EPA categorizes the air pollution impacts this way:

- Emissions from trucks and drilling equipment [noise, particulates, $\mathrm{SO}_{2}, \mathrm{NO}_{x}$, non-methane volatile organic compounds (NMVOCs), and CO].

- Emissions from natural gas processing and transportation (noise, particulates, $\mathrm{SO}_{2}, \mathrm{NO}_{x}, \mathrm{NMVOC}$, and $\mathrm{CO}$ ).

- Evaporative emissions of chemicals from waste water ponds.

- Emissions due to spills and well blowouts (dispersion of drilling or fracturing fluids combined with particulates from the deposit). ${ }^{72}$
According to the 2010 U.S. Greenhouse Gas Emissions Inventory, ${ }^{72}$ the natural gas industry ${ }^{\dagger \dagger}$ represented nearly a third of total methane emissions in the United States in 2010 , the largest single category, and is also the fourth largest category of $\mathrm{CO}_{2}$ emissions. ${ }^{*}$ EPA, which produces the U.S. GHG inventory, significantly increased estimates of methane emissions from the natural gas industry for the 2009 inventory year, resulting from a change in its assessment of emissions from four activities, the most important of which were well venting from liquids unloading (attributed only to conventional ${ }^{\S}$ wells by EPA), gas well venting during completions, and gas well venting during well workovers $* * .72$ The sum of these changes more than doubled the estimate of methane emissions from natural gas systems from the 2009 inventory compared to the 2008 inventory. EPA acknowledges what is well understood-the estimates of GHG emissions from the natural gas sector are highly uncertain, with a critical lack of empirical data to support GHG emission assessments. ${ }^{72}$ This is especially acute for production of unconventional gas resources. Data gathering to support reassessment of EPA's U.S. GHG inventory and potential regulations is underway. Brandt et al. found overall natural gas system emissions to be "...about $25-75 \%$ higher than EPA estimate[s]. $" 76$

The practice of "green" completions ${ }^{\dagger \dagger \dagger}$ has been introduced to reduce volatile organic compound (VOC) emissions, yielding co-benefits for methane emission reductions. EPA's 2012 New Source Performance Standards and Hazardous Air Pollutant regulations for oil and gas production include green completion requirements and other controls that will reduce emissions of VOCs and certain hazardous air pollutants. ${ }^{77}$ These regulations will have the co-benefit of reducing fugitive methane emissions associated with natural gas production. ${ }^{78}$ As EPA notes, "A key component of the final rules is expected to yield a nearly $95 \%$ reduction in VOCs emitted from more than 11,000 new hydraulically fractured gas wells each year. The estimated revenues from selling the gas that currently goes to waste are expected to offset the costs of compliance, while significantly reducing pollution from this expanding industry. The EPA's analysis of the rules shows a cost savings of $\$ 11$ million to $\$ 19$ million when the rules are fully implemented in 2015."78 A number of states, various stakeholders, and the SEAB have also called for additional New Source Performance Standards regulations directed specifically at the problem of fugitive methane emissions from unconventional natural gas production. ${ }^{77}$ Colorado has recently become the first state in the country to adopt regulations that directly address methane emissions from oil and gas production. ${ }^{79}$

With respect to methane emissions from the midstream and downstream segments of the natural gas supply chain (transmission, storage, and distribution), there are no current federal or state regulatory programs that directly address such emissions even though studies indicate that these segments account for the majority of emissions from the sector. ${ }^{*} \$$ The Federal Pipeline \& Hazardous Materials Safety Administration (PHMSA), for example, does not currently consider methane emissions 


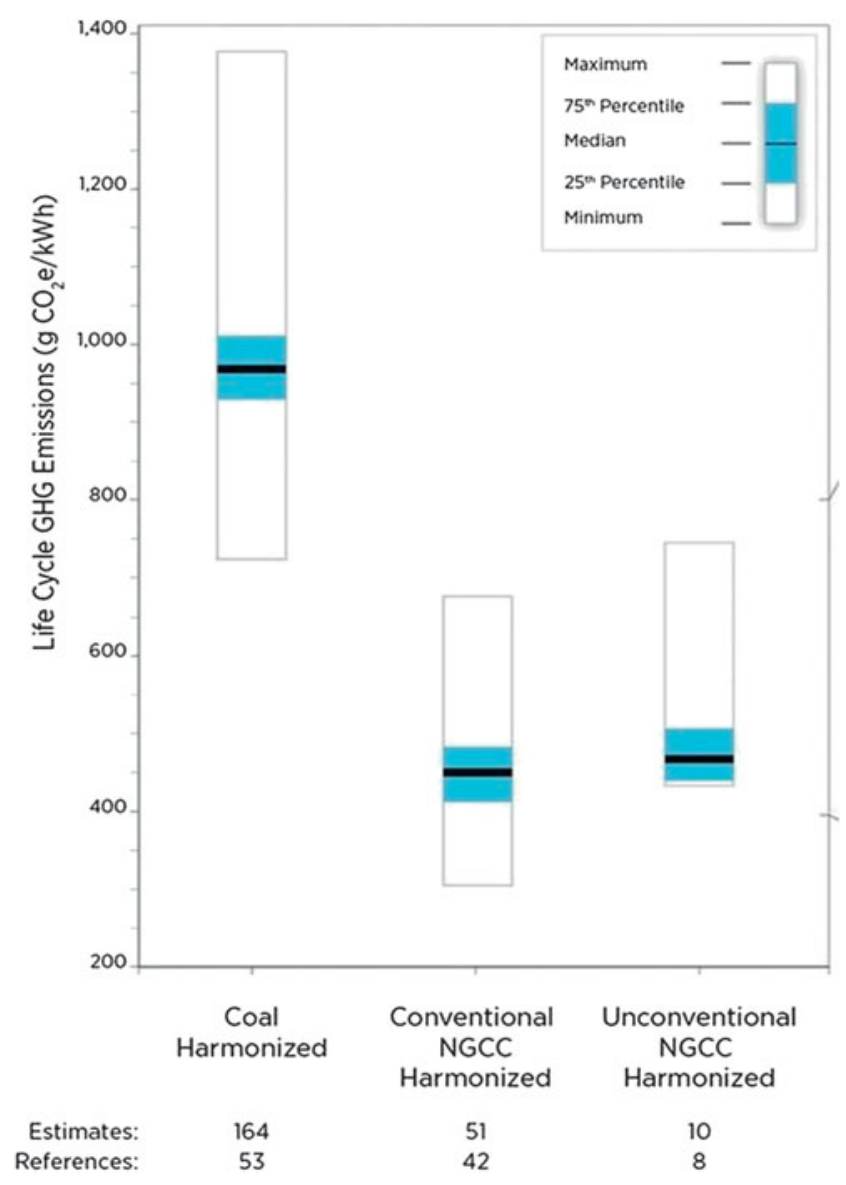

Figure 8. Synthesis of prior estimate of life cycle GHG emissions from natural gas (conventionally produced and unconventionally) and coal used for electricity generation after methodological harmonization. ${ }^{42}$

due to pipeline leaks when promulgating pipeline standards for leak detection and repair. $\$ \S \S$ The Federal Energy Regulatory Commission (FERC) does not currently consider direct GHG impacts of new natural gas pipelines in exercising its authority over the siting of interstate pipelines. ${ }^{* * *}$ And EPA does not currently regulate leaks or emissions from natural gas transmission or storage under its Clean Air Act authority. Likewise, state authorities that regulate intrastate pipelines and local distribution systems have not directly addressed methane leaks and emissions from those systems, although a number of states have adopted pipeline modernization and replacement programs. ${ }^{\dagger \dagger \dagger \dagger}$

More widely, the EPA uses the Natural Gas STAR program, a voluntary partnership with recommended actions looking across the gas sector in the areas of:

Gas production and processing.

- Perform reduced emission completions.

- Install plunger lifts (improves well production while reducing gas losses).

- Aerial leak detection using laser and/or infrared technology.

- Eliminate unnecessary equipment and/or systems.
Oil production.

- Install vapor recovery units on crude oil storage tanks.

- Route casing head gas to vapor recovery unit or compressor for recovery and use or sale.

Gas storage.

- Convert gas pneumatic controls to instrument air.

- Replace bidirectional orifice metering with ultrasonic meters.

- Reduce methane emissions from compressor rod packing systems.

Gas transmission.

- Directed inspection and maintenance at compressor stations.

- Use fixed/portable compressors for pipeline pumpdown.

- Install vapor recovery units on pipeline liquid/condensate tanks.

Gas distribution.

- Directed inspection and maintenance at surface facilities.

- Identify and replace high-bleed pneumatic devices.

- Survey and repair leak.

An emerging literature has attempted to estimate GHG emissions from unconventional natural gas production, based on the limited available information. Measurement of GHGs in the atmosphere, if they could be reliably attributed to specific sources, would be the ideal methodological approach. However, such measurements are expensive, attribution is challenging, and only a few studies have been published to date, such as Pétron et al. (2014).$^{80}$ Many other studies use engineering-based modeling, based on as much empirical information as is possible to assemble. Much of this emerging literature is guided by the methods of LCA, which in this context aims at estimating all GHG emissions attributable to natural gas used for a particular function: electricity, transportation, or primary energy content (e.g., heat). Attributable emissions are those from any activity in the process chain of producing the natural gas-from exploration and well pad preparation to drilling and completion-processing it to pipeline quality, transporting it to the location of end use, and combustion. In addition, the construction, operation and maintenance, and end-of-life decommissioning of the end use technology are also considered.

LCAs are typically performed for the purpose of comparing the results from one system to another. + *t Natural gas, once processed for pipeline transmission to end use customers, is a homogenous product, undifferentiated by source. End-use combustion of the natural gas has by far the largest contribution to life cycle GHG emissions (as is true for any fossil-fueled combustion technology). It is not a point of differentiation between conventional and unconventional natural gas, but remains a significant factor relative to the use of coal, nuclear, 
or renewable energy options as well as for transportation. Therefore, the attention here focuses on the activities associated with production of natural gas because they are the points of potential differentiation between unconventional and conventional natural gas. Given current regulatory and scientific attention to emissions from the natural gas industry and opportunity provided by the unique data sources used in this report, we additionally focus on emissions from natural gas processing. We rely on the multitude of previously published LCAs of conventionally produced natural gas, ${ }^{81-86}$ updated for recent changes in understanding and harmonized for methodological inconsistency, for comparison to the results of this study. We also compare these results to those for coal-fired electricity generation based on a systematic review and harmonization of that LCA literature, because coal has been the largest energy source for electricity in the United States over the last 50-plus years. ${ }^{81}$

Prior research comparing life cycle GHG emissions of electricity generated from shale gas to conventional gas and other energy sources has been inconclusive and remains uncertain. Both the magnitude and direction of difference reported in these publications vary. See, for example, Howarth et al. $(2011)^{82}$; Jiang et al. $(2011)^{83}$; and Stephenson et al. (2011). ${ }^{84}$ This is despite their reliance on very similar data sources (mostly EPA's GHG emission inventory and supporting documentation). Uncertainty in the underlying data sources drives the uncertainty in published results. Furthermore, inconsistent approaches to data use and other assumptions thwart direct comparison of the results of these studies and the development of collective understanding. Separately, Heath et al. have examined this literature using a meta-analytical technique called harmonization that clarifies the collective results of this emerging literature by adjustment to more consistent methods and assumptions. ${ }^{85-86}$ In these publications, the authors elucidate differences between previously published estimates of life cycle GHG emissions from combustion of shale gas for power production and key sensitivities identified in the literature. Key sensitivities include estimated ultimate recovery (EUR) and lifetime (years) of wells; emissions and emissions reduction practices from well completion and workover; and emissions and emission reduction practices from well liquids unloading, all of which vary from basin to basin and from operator to operator. A key conclusion from the assessment of previous estimates of unconventional gas life cycle GHG emissions is that given current uncertainties, it is not possible to discern with a high level of confidence whether more GHGs are emitted from the life cycle of shale gas or conventional gas used for electricity generation.

The peer reviewed scientific literature fairly consistently indicates a significant difference in emissions from natural gas processing, transmission and distribution compared to "official" inventories. ${ }^{76}$ These differences will not be resolved without major effort, because current estimates are based on decades-old and inadequately sampled measurements of methane leakage. Better measurement technologies and more comprehensive sampling across the many segments, regions, operators, gas types, and technologies are necessary to ensure that bottom-up inventories and LCAs can accurately estimate the GHG emissions profile of gas.

Top-down assessments are likewise in a state of early scientific investigation [see, e.g., Pétron et al., 2014 (Ref. 80)] and have been restricted to limited regions or slices of time. Despite disagreement in methods and interpretations, top-down assessments have repeatedly found that bottom-up emission estimates cannot explain the concentrations of methane measured in the atmosphere. ${ }^{76}$ This has raised questions about the true emissions profile of natural gas production and use.

The natural gas leakage rate is another critical parameter determining the climate impact of natural gas. Leakage can be defined as the proportion of produced natural gas that is released to the atmosphere either intentionally through standard practice and component/system design, or unintentionally through fugitive emissions. Alvarez et al. (2012) have calculated the maximum leakage rate for natural gas to provide climate benefit, over all time scales, compared to the fuel it would displace. ${ }^{87}$ Their results suggest that maximum leakage rates differ significantly depending on the application. Emissions could be as high as $3.2 \%$ for benefits to be realized in the electric sector displacing coal, but only as high as $1.2 \%$ for beneficial use in the transportation sector. Preliminary emission estimates based on atmospheric research suggest that current leakage rates could be significantly higher than these tipping points. ${ }^{76,88}$ The increased attention to methane emissions has risen due to a combination of factors including new literature and dramatically increased production in the United States. The climate mitigation perspective was furthered by the recent update to global warming potentials by the Intergovernmental Panel on Climate Change (IPCC). ${ }^{89}$ Here, specifically, the IPCC updated the 25- and 100-year global warming potentials of methane from 84 to 86 , and 28 to 34 , respectively. $\$ \S \S$

Atmospheric measurements may be used for verification of bottom-up assessments, but are not likely to achieve the resolution necessary to support source prioritization. Therefore, it is also critical to develop analytical approaches to reconcile bottom-up and top-down assessments, which are currently in such disagreement. Better agreement between these two approaches could be explored by improving measurement technologies, modeling downscaling techniques, and improving understanding of the gas composition profile of sources. Significantly more measurement, verification, continuous monitoring, and rapid leak repair methods and practices are needed to assure minimal methane emissions.

Recent research ${ }^{76}$ has explored the wider system impacts of methane leaks from the whole gas system. They discuss gas as a "potential" bridge fuel. We use their language as a bridge to Section "Implications for pathways toward a sustainable energy future," noting a summary conclusion of Brandt et al.'s seminal article: "Our findings show that natural gas can be a bridge to a sustainable energy future, but that bridge must be traversed carefully. Current evidence suggests that leakages may be larger than official estimates, so diligence will be needed to ensure 
that leakage rates are actually low enough to achieve sustainability goals. ${ }^{" 76}$

\section{Implications for pathways toward a sustainable energy future}

This section reviews the literature related to the role of conventional and unconventional gas in energy scenarios with a focus on environmental considerations such as air pollution and GHG emissions. In doing so, it considers the assertions of natural gas as a "bridge" fuel in the context of the larger energyeconomy system.

Recent U.S. shale gas developments have had more impact on the electricity sector than any other sector to date..$^{90}$ Opportunities exist to advance energy, economic, and environmental goals in other sectors-including transportation, industry, and buildings-although specific barriers must first be overcome. ${ }^{91}$

Figure 9 illustrates the rapid growth of natural gas generation in the U.S. power sector since 2005. Natural gas demand for power generation has grown by more than 6.8 billion cubic feet per day since 2008 . The power sector accounted for nearly $36 \%$ of all natural gas demand at the end of 2012, up from $29 \%$ in 2008. ${ }^{92}$ During the same period, consumption of coal for electricity generation dropped by nearly $21 \% .{ }^{93}$ The initial impact of this fuel switching on GHG emissions depends on at least two factors: life cycle GHG accounting assumptions and "consequential" impacts associated with greater exports of U.S. coal supplies. ${ }^{42,94}$

Over the medium term, the contribution of natural gas to the U.S. power generation demand (and related GHG emissions) will depend on a number of factors. Illustrative examples presented in Fig. 10(a) show a range of natural gas contributions across a number of possible scenarios, including natural gas availability and price, as well as other key policy, regulatory, and technology factors. Natural gas contributions to U.S. power may either remain relatively flat to 2030 (low supply/high prices or low cost renewables), or nearly double under low cost availability and more stringent GHG policy [e.g., upper bound of the Clean Energy Standard (CES) scenarios] in which natural gas displaces a significant amount of coal generation by 2030 . By 2050 , in the baseline scenarios, ${ }^{* * * *}$ gas could represent from 28 to $38 \%$ of power-sector generation compared to the $25-30 \%$ in recent years as shown in Fig. 9. Attributes of the baseline scenarios include rising power demand, stable GHG emissions, and slowly rising electricity prices that reflect natural gas availability and prices. In a coal retirement scenario, natural gas, and wind to a lesser extent, replaces coal-based generation. Under a carbon-constrained scenario, ${ }^{\dagger \dagger \dagger \dagger \dagger}$ U.S.

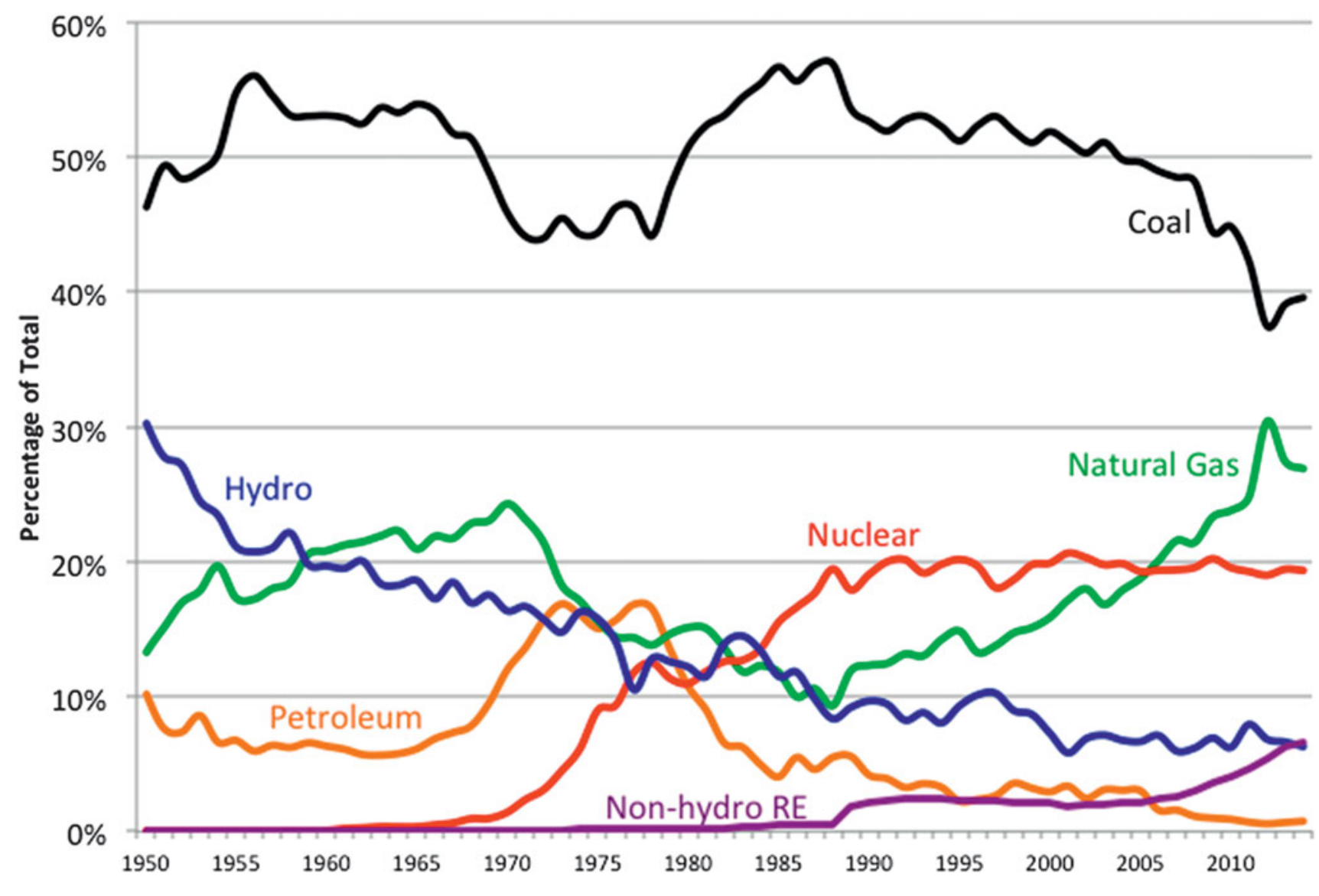

Figure 9. Change in U.S. generating mix from January 1950 to August 2014 (derived from EIA "Electric Power Monthly," October 2014). 
a)

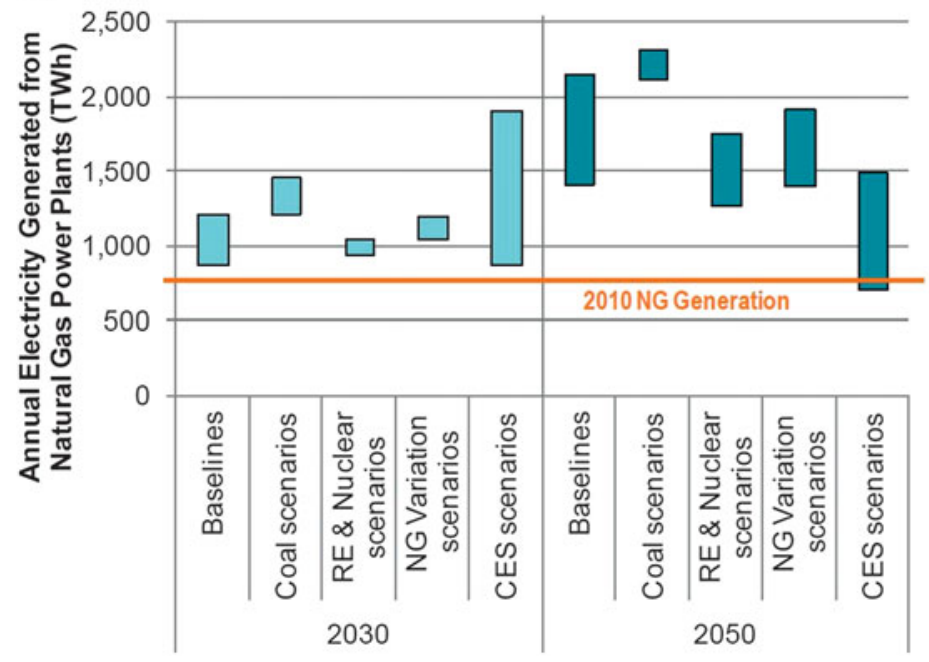

b)

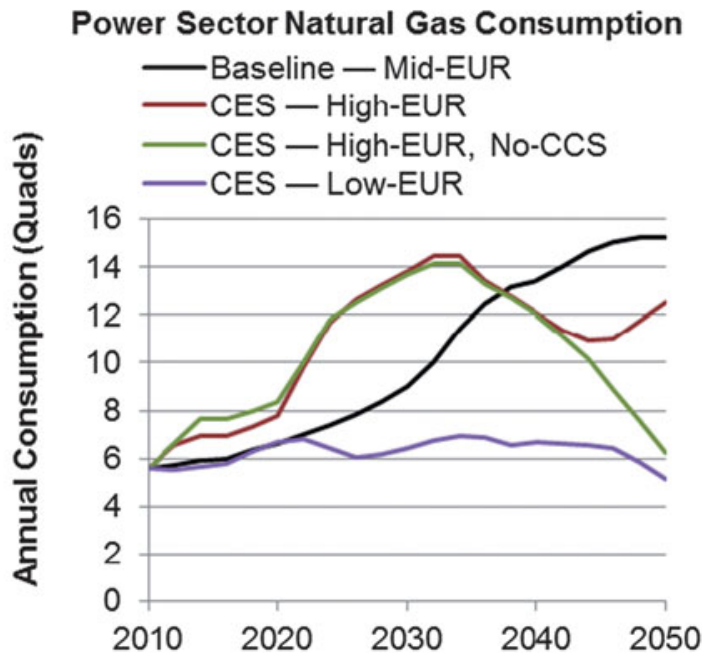

Figure 10. (a) Range of electricity generation from natural gas power plants under different scenarios and (b) natural gas consumption for a baseline and low carbon scenarios with high or low EUR and without CCS. ${ }^{42}$

power-sector carbon dioxide emissions would decrease by $90 \%$ between 2010 and 2050; natural gas demand would remain relatively flat under a low resource estimate/high price regime but roughly double through 2030 if prices remain competitive as shown in Fig. 10(b). Natural gas demand for power would return to, e.g., 2010 levels by 2050 if carbon capture and sequestration (CCS) were not a viable and competitive option due to the increased stringency of the carbon constraint in a CES scenario. Notably under a high gas price and strong carbon constraint scenario, as discussed below in more detail, large quantities of variable renewable energy and flexible gas generation work synergistically to meet the stringent GHG emissions constraint while maintaining system reliability requirements.

Natural gas has approximately half of the carbon emissions per unit energy as coal, but is still a fossil fuel and therefore has more direct carbon emissions than energy forms such as wind, solar, and nuclear power. Ignoring those for the time being, burner-tip carbon dioxide emissions-that is, emissions attributable to burning fossil fuels at the power plant-in the U.S. power sector have declined by approximately $13 \%$ since 2008 . Rising natural gas prices relative to coal in 2013-14 has resulted in some shift back to more coal generation.

Despite the newfound abundance of domestic natural gas, generation planners and utility regulators retain their longstanding concerns over natural gas prices and volatility. ${ }^{95-96}$ Ensuring balanced and risk-appropriate generation portfolios may be a key challenge going forward for many. Furthermore, natural gas may have a limited role in a carbon-constrained world. In the long term at least, natural gas is still a fossil fuel, and limiting $\mathrm{CO}_{2}$ concentrations in the atmosphere ultimately requires that net $\mathrm{CO}_{2}$ emissions decline toward zero. Carbon capture and sequestration (CCS) could help address that barrier to gas use, and coal use for that matter, although many challenges must be resolved to deploy CCS. ${ }^{13,42,97-99}$
The rapid expansion of shale gas has created opportunities and challenges in the U.S. energy sector. How long the ascendancy of natural gas in the electric sector will last will be a function of a wide variety of market and policy factors. The story of unconventional gas is evolving rapidly, and, in some cases, unexpectedly. Robust and up-to-date analysis will remain critical to informing the key decisions that must be made by all types of stakeholders in the energy and environmental arenas.

Reporting on the narrative of natural gas as a bridge fuel began prior to the 2010 Massachusetts Institute of Technology study by Moniz et al. on "The Future of Natural Gas." That report [as reported on by Scientific American in 2010 (Ref. 100)] noted, however, that "Under a scenario that envisions a federal policy aimed at cutting GHG emissions to $50 \%$ below 2005 levels by 2050 , researchers found a substantial role for natural gas." In general, that sentiment has remained, and although the "bridge" narrative has gone through numerous sets of often competing analysis, no precise definition of what in fact constitutes a "bridge fuel" seems to exist. That narrative discusses how natural gas might be optimally used to advance toward a "low-carbon" future by displacing coal in the power sector, and oil in transport (to a lesser degree). The crux of the discussion ${ }^{101-103}$ lies not only in how much benefit in terms of mitigation gas growth would provide, but also the various issues surrounding fugitive emissions from the gas system. Michael Levi described his findings:

"...global climate stabilization scenarios where natural gas provides a substantial bridge are generally absent from the literature, making study of gas as a bridge fuel difficult. Here we construct a family of such scenarios and study some of their properties. In the context of the most ambitious stabilization objectives (450 ppm $\mathrm{CO}_{2}$ ), and absent carbon 
capture and sequestration, a natural gas bridge is of limited direct emissions-reducing value, since that bridge must be short. Natural gas can, however, play a more important role in the context of more modest but still stringent objectives (550 ppm $\mathrm{CO}_{2}$ ), which are compatible with longer natural gas bridges. Further, contrary to recent claims, methane leakage from natural gas operations is unlikely to strongly undermine the climate benefits of substituting gas for coal in the context of bridge fuel scenarios." 104

Other teams, for example Jacoby and $\mathrm{O}^{\prime}$ Sullivan, ${ }^{105}$ investigate the potential impact of abundant, low cost natural gas and describe the results of their modeling exercise this way: "The emergence of shale gas supplies is a boon to the U.S. economy and an aid to potential climate policy. The lower-cost energy is projected to stimulate greater economic growth over the period to 2050 , and to ease the task of GHG control over coming decades."

The use of natural gas as part of a sustainable energy future is also often discussed in terms of its relationship with renewable energy as well as other power sector options. Figure 11 presents a schematic of typical risks in power sector development and how both natural gas and renewable energy relate to each. As discussed by Lee et al., ${ }^{106}$ natural gas and renewables have complementary risk profiles that span policy, regulation, price volatility, and resource variability. Portfolio approaches range from hybrid system design, to colocation of assets, to financial portfolios of noncorrelated or collocated assets. In the electricity sector, their principal finding was that "A diverse electricity portfolio can maximize the benefits and minimize the risks of each portfolio component and, most importantly, provide a robust platform for the future. Natural gas and renewable energy interactions span economic, technical, environmental, and institutional aspects. Combined pursuit of both can significantly reduce overall portfolio risks in the electric power sector." These synergies may help achieve both near-term and long-term decarbonization in countries or regions with sufficient renewable resources, when combined with fast-ramping

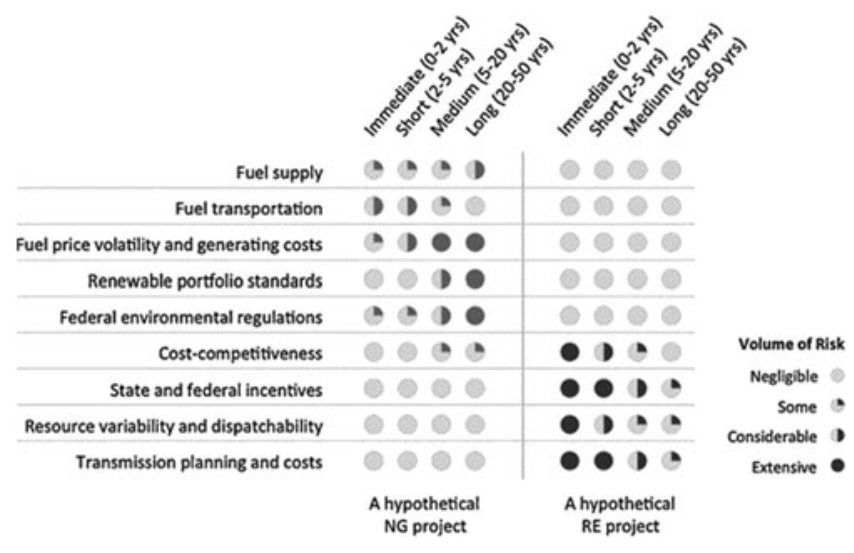

Figure 11. Risks in the power sector for natural gas and renewable energy developments. ${ }^{106}$ natural gas power generation used to provide the needed flexibility and capacity.

Returning to the role of gas in the energy mix from a climate perspective, Wood et al. do not find the bridge argument compelling. They note that "...while being promoted as a transition route to a low carbon future, none of the available evidence indicates that this is likely to be the case. It is difficult to envisage any situation other than shale gas largely being used in addition to other fossil fuel reserves and adding a further carbon burden." 12 Still, the narrative of using natural gas as a bridge fuel remains politically attractive. ${ }^{107}$ Similarly, Newell and Raimi report, "Our main conclusions are that natural gas can help reduce GHG emissions, but in the absence of targeted climate policy measures, it will not substantially change the course of global GHG concentrations."98 This is consistent with the findings from a set of 14 diverse policy models evaluated in Energy Modeling Forum (EMF) 26: "Overall shale gas development and use across the breadth of [U.S.] scenarios analyzed have relatively modest impacts on the emissions of carbon dioxide, sulfur dioxide, and nitrogen oxides." 108 This conclusion also appears to translate to the global stage. Emphasizing the same causal effects as the EMF and Newell and Raimi studies, McJeon et al. report results from five global models examining the effect of more abundant natural gas resources and conclude: "The core finding of this research is that more abundant natural gas could substantially change the global energy system over the decades ahead without producing commensurate changes in emissions or climate forcing. The result stems from three effects: abundant gas substituting for all energy sources; lower energy prices increasing the scale of the energy system; and changes in non- $\mathrm{CO}_{2}$ emissions." 109

While there is an increasing number of studies looking at the role of natural gas in climate forcing in the absence of new policies and measures to limit climate change, there are relatively few studies that have examined the role of more abundant natural gas in the context of policies and measures to limit climate forcing. EMF 26 (Ref. 108) is a notable exception to that generalization and current efforts are continuing under a new effort (EMF 31). More research in this area is needed.

In general, the literature finds that more abundant natural gas carries a variety of implications for sustainability including:

- U.S. natural gas demand for power generation would grow rapidly, more than doubling from the 2010 level by 2050, in the reference, or baseline, scenario. Figure 10 illustrates the range of natural gas power generation in all scenarios from Logan et al. (2013). ${ }^{13}$ However, the principal conclusion of research to date ${ }^{1,98,108-109}$ is, as Newell and Raimi put it, that "Shale gas will likely not substantially change global GHG concentrations on its own."98 The increased supply of natural gas lowers the natural gas price, making natural gas more competitive relative to all other energy competitors, both fossil 
and non-fossil forms with only a modest net effect on carbon dioxide emissions without policies explicitly designed to limit competitiveness relative to renewable energy forms. McJeon et al. ${ }^{109}$ point out that the same is true for the global energy-economy system when the net climate forcing from all GHGs is considered.

- Several studies ${ }^{1,98,108-109}$ report that lower gas prices result in an energy-economy feedback effect; that is, lower gas prices increase overall economic activity, i.e., GDP. This in turn increases demands for all energy forms, including fossil fuels.

- To the extent that abundant gas occurs locally, changes in GHG emissions in one region can have consequences for emissions in another region. For example, the IEA reported that natural gas displacement of coal in the United States over the period 2006 to 2010 led to an increase in coal use in the Europe. ${ }^{110}$

- The inclusion of non- $\mathrm{CO}_{2}$ (e.g., methane, $\mathrm{N}_{2} \mathrm{O}$, halocarbons, $\mathrm{CO}$, and $\mathrm{NO}_{x}$ ) GHG emissions changes the overall analysis marginally. ${ }^{98}$ In the absence of climate policy, the expansion of natural gas leads to increased methane losses in gas production, transmission, and distribution, since natural gas is primarily methane. Fugitive natural gas emissions are offset to some degree, but not entirely, by reductions in methane losses associated with coal production. 109

- The displacement of coal by gas increases radiative forcing through the reduction in sulfur emissions, which has a strong regional cooling effect on climate, while conferring a local air quality benefit (reduced SOx related emissions). However, the net climate effect of changes in sulfur emissions is subject to substantial uncertainty. ${ }^{98}$

In summary, natural gas (both conventional and unconventional) can offer GHG mitigation benefits relative to coal, if methane emissions are small enough. Many detailed studies indicate that official inventory estimates (such as those reported by EPA or other national reporting bodies) may underestimate the methane emissions. ${ }^{76}$ Significant work is needed to measure and verify methane emissions across the full production, transportation, and distribution value chain. The methane emission levels also significantly effect whether natural gas has a net life cycle GHG benefit, or not, relative to other transportation fuels. ${ }^{87}$ Thus, if natural gas is to help mitigate climate change, it will do so primarily by displacing coal. However, in the long term, natural gas itself, through displacement of coal or other fossil fuels, will not significantly alter long-range climate projections if greater availability stimulates additional energy consumption through either lower energy prices or increased economic activity. Other zero carbon technologies such as renewables or CCS will be needed to achieve carbon mitigation goals. Furthermore, the same economic forces that drive the substitution of natural gas for coal also work to the disadvantage of nongreenhouseemitting technologies such as nuclear, wind, and solar power.
McJeon et al. report that policies such as renewable portfolio standards can limit the substitution of gas for nonemitting technologies. ${ }^{109}$

\section{Some areas for further research}

This section considers the need for further research on new techniques and technologies that may improve our understanding of the environmental impacts of conventional and unconventional natural gas.

Ongoing and intensified research is needed to ensure the foundations for good long-term decision-making and the development of sound and sustainable regulation and policy. It remains critical to consider and weigh the wider set of costs and benefits to society, including economics, security, and public health. Some considerations for further research in this area can be found in Bazilian et al. (2014). ${ }^{111}$ Other technologies being explored by both academia and industry include:

- New applications of using recycled brackish, flowback, and produced water instead of fresh water coupled with green completions and tighter leakage controls in transmission and distribution will all help ensure better developments and improved social license to operate benefits.

- Newer technologies such as nonhydro fracking-using butane, propane, $\mathrm{CO}_{2}$, or nitrogen or other substitutes ${ }^{*+*}$ - may improve the LCA of unconventional gas even further but these approaches face economic and scale challenges.

- "Tracers" injected into fracking water are also emerging as an interesting way to better understand leakage and diffusion. $\$ \S \S \S \S$

- Improved low-cost, ubiquitous monitoring equipment throughout the transmission and distribution system may also provide the data required to vastly improve system overall performance.

- Nanotechnologies that lead to improved proppants. ${ }^{* * * * *}$

- Improved and lower cost imaging equipment to detect methane emissions.

A number of questions can be prioritized in the water and GHG emissions area, such as:

- Water:

- What are the water contamination pathways and risks that are adequately or inadequately addressed by current industry practices?

- What is the probability (quantitative) that water resources will be contaminated based on existing industry practices? What is the probability (quantitative) that water resources will be contaminated if alternative water management practices are adopted?

- What are the most common methods industry is currently using to minimize risks to water resources? 
- GHG emissions:

- What technological options exist for improved monitoring of methane emissions? How can breakthroughs in sensors and data handling be put to use in managing methane leakage?

- What improvements in technology, infrastructure, process, and practice can be made to reduce methane emissions?

- How can (or should) new estimates of methane emissions be included in regulatory air quality processes such as emissions inventories and modeling for state implementation plans?

- Will the availability of abundant natural gas make it easier or more difficult to limit climate forcing, in the near term and/or the long term, in the U.S./World?

- Will natural gas producers benefit under climate policies or be disadvantaged?

Technological advances will need to be coupled with improved analysis and communication around risks and benefits to consumers, landowners, and society in general to create and realize benefits. To that end, SEAB cautioned that, "whether its [SEAB recommendations] approach is followed or not, some concerted and sustained action is needed to avoid excessive environmental impacts of shale gas production and the consequent risk of public opposition to its continuation and expansion." 66

\section{Conclusions}

This article provided a brief overview of two of the key areas of environmental impact associated with natural gas production and use-water and GHG emissions. All phases of shale gas development have the potential to affect either the quantity or quality of local water resources. Hydrofracking can be water intensive, and water resources in many areas where shale plays exist are already experiencing groundwater depletion due to drought conditions and over-consumption by domestic, agricultural, and industrial sectors. Industry and stakeholder groups have not yet established a standard set of BMPs or principles for managing water use or water quality, but many have innovated to reduce water demands, increase recycling and reuse, and carefully manage disposal of solids. Further, there is little consistency in regulations from one state to the next regarding water and wastewater management practices associated with unconventional oil and gas development. A full characterization of the sources and the mechanisms of actual and potential contamination is needed, followed by an examination of practices and procedures to eliminate or mitigate the risks of depletion and contamination of water resources.

Related to GHG emissions, natural gas (both conventional and unconventional) can offer GHG mitigation benefits relative to coal, if methane emissions are small enough. However, the same economic advantage that spurs the substitution of gas for coal also operates to substitute gas for nonemitting energy forms such as nuclear, wind, and solar. Natural gas can have a net life cycle GHG benefit, or not, relative to other transportation fuels, but this strongly depends on methane emissions, which would need to be less than $1 \%$. Thus, if natural gas is to help mitigate climate change, it will do so primarily by displacing coal.

It appears likely that natural gas-whether unconventional or not-will form an important part of the energy mix over the forthcoming decades. Thus, from a pragmatic perspective, the development and adherence to stringent environmental and public health related principles and practices (perhaps through regulation) are critical to ensuring that natural gas can contribute in optimal ways to support the "vector" of a sustainable energy pathway over the next 50-100 years. However, in the long term, natural gas itself, through displacement of coal or other fossil fuels, will not significantly alter long-range climate projections. Other zero carbon technologies such as renewables or CCS will be needed to achieve carbon mitigation goals. Policies that limit the effect of economic forces driving the penetration of natural gas against all fuels, including renewable energy forms, can help ensure that natural gas substitutes primarily against coal.

The pace of the U.S. shale gas revolution has naturally led to several existing gaps for future research and development related to environmental impacts. Specifically, the transparent and ongoing robust treatment of the areas of water use and GHG emissions will be critical for the successful and maintained development of shale gas in the United States and abroad. There is a need for increased availability of transparent and accessible data in all of these areas, and this is likely done best through a partnership with industry. Other countries and regions (like the European Union) are carefully watching the development of the shale gas sector in the United States-especially for the development and enforcement of associated environmental and public health regulations.

\section{NOTES}

"There are analysts who think that the gas and oil "revolution" will be short lived due to, inter alia, a lack of understanding of 20-40 year time horizons and decline rates (see, e.g., Berman A.E. and Pittinger L.F.: U.S. Shale Gas: Less Abundance, Higher Cost: The Oil Drum (August 5, 2011); Hughes J.D.: Energy: A reality check on the shale revolution. Nature 494, 307-308 (2013); Inman M.: Natural gas: The fracking fallacy. Nature 516, 28-30 (2014). We do not attempt to evaluate the strengths and weaknesses of those arguments here.

$\uparrow$ The U.S. drought monitor characterizes drought intensity as abnormally dry, moderate drought, severe drought, extreme drought, and exceptional drought. http://droughtmonitor.unl.edu

\$ http://www2.epa.gov/hfstudy/hydraulic-fracturing-water-cycle

$\S$ For interested readers, Richardson et al. (2013) review the common water quality and water quantity risk mitigation techniques that are being used and which states are using them. ${ }^{44}$

** Trade-secret additives have been exempted from most disclosure practices. ${ }^{\dagger}$ For purposes of the GHG inventory, the natural gas industry includes exploration, production, processing, transmission, storage, and distribution of natural gas to the end user. ${ }^{72}$

柿 According to the 2012 EPA Inventory, in 2010, total U.S. GHG emissions have been estimated as $6822 \mathrm{Tg}$ or million metric tons of $\mathrm{CO}_{2} \mathrm{e}$ (Ref. 72). Of this total, $84 \%$ were from $\mathrm{CO}_{2}$, with most of the remaining (10\%) from methane. Direct emission from the combustion of fuels, including natural gas for electricity generation, contributes $2258 \mathrm{Tg}$ of $\mathrm{CO}_{2}$ or $33 \%$ of total GHG emissions. Natural gas systems contribute $247 \mathrm{Tg}$ of $\mathrm{CO}_{2} \mathrm{e}$ or $3.6 \%$ of total emissions, $87 \%$ from emissions of methane. The 2014 EPA Inventory updated 2010 total emissions to $6875 \mathrm{Tg}$, while the proportions remained approximately the same [Inventory of 
U.S. Greenhouse Gas Emissions and Sinks: 1990-2012. EPA 430-R-14-003. (U.S. Environmental Protection Agency, Washington DC, 2014)].

$\S \S$ Defined as any nonstimulated well. This report follows EPA in recognizing

"that not all unconventional wells involve hydraulic fracturing, but some conventional wells are hydraulically fractured, which is assumed to balance the over-estimate." 72

*** The frequency of which has since been reduced from $10 \%$ of wells per year to $1 \%$ of wells per year. ${ }^{72}$

$\dagger^{\dagger \dagger}$ Green completions are systems to reduce methane losses during well completions. 抹 In 2012, there were actually more methane emissions associated with these midstream and downstream segments than with natural gas production. According to the April US GHG inventory, some $34 \%$ of methane emissions from the natural gas sector are associated with transmission and storage while another $20 \%$ are attributed to the distribution system. See Inventory of U.S. Greenhouse Gas Emissions and Sinks: 1990-2012, Energy section, at 3-63 (April 2014). §§ See Ref. 49 CFR § 195.6.

**** See Section 7 of the Natural Gas Act, 15 U.S.C. $\$ 717$, which requires a certificate of public convenience and necessity from FERC before constructing and operating an interstate natural gas pipeline. As part of the process for issuing such certificates, FERC performs an environmental review. 40 C.F.R. 1508.7. These environmental reviews sometimes include very general language on climate impacts, but have not, to date, addressed the issue of methane emissions or leaks from pipelines. See, e.g., FERC, Tioga Area Expansion and Sabinsville to Morrisville Projects Environmental Assessment, Docket No. CP12-19-000 (Nov. 2012). See also FERC East Side Expansion Project Environmental Assessment, Docket No. CP14-17-000 (Aug. 2014); FERC Environmental Assessment Ohio Pipeline Energy Network Project, Texas Eastern Transmission, Docket No. CP14-68000 (Aug. 2014); Texas Eastern Appalachia to Market 2014 Project, Docket No. CP13-84-000 (Sept. 2013).

$\nmid \uparrow \dagger$ Thirty-eight states have established pipeline and distribution system replacement programs as part of their general rate regulation of natural gas utilities. See Natural Gas Utilities Take Steps to Further Reduce Emissions, AGA website (June. 2014), http://www.aga.org/Newsroom/news-releases/ 2014/Pages/Natural-Gas-Utilities-Take-Steps-to-Further-Reduce-Emissions.aspx; American Gas Foundation, Gas Distribution Infrastructure: Pipeline Replacement and Upgrades (July 2012).

林末 For interested readers, many texts describe LCA principles and methods, such as R. Horne, T. Grant, K. Verghese, Life Cycle Assessment: Principles, Practice and Prospects, Csiro Publishing, 2009.

$\S \S s \S$ The Global Warming Potential (GWP) is defined as the time-integrated radiative forcing due to a pulse emission of a given component, relative to a pulse emission of an equal mass of $\mathrm{CO}_{2}$. The updated values include carbon-climate feedbacks.

***** A baseline scenario serves as a point of comparison with other alternative scenarios. The baseline assumes a fairly static view of the future, so it, and all alternative scenarios, should not be considered forecasts or predictions of the future. $\nmid \dagger \dagger \dagger$ Logan et al. modeled carbon constraint as a CES, a particular policy formulation that allocates low carbon credits to renewables and nuclear, and half credit to natural gas, and $90 \%$ credit to fossil fuels with CCS. See Logan et al. (Ref. 42) for more details.

赫浾 See, e.g., GASFRAC Energy Services Inc., a fracturing services and consulting company: http://www.gasfrac.com/

$\S \S \S \S \S$ See BaseTrace, e.g., a well-specific DNA-based tracer for hydraulic fracturing fluids: http://www.basetrace.com/

****** See OxFrac, e.g., on an ultralight nanotech ceramic proppant developed by Oxane Materials, Inc. (http://www.oxanematerials.com/)

\section{REFERENCES:}

1. U.S. Energy Information Administration (EIA): World Shale Gas Resources: An Initial Assessment of 14 Regions Outside the United States. Prepared by Advanced Resources International (Energy Information Administration, Washington, DC, 2011).

2. Medlock K.B. III, Jaffe A.M., and Hartley P.R.: Shale Gas and U.S. National Security (Baker Institute for Public Policy, Rice University, Texas, 2011).

3. National Petroleum Council: Balancing Natural Gas Policy: Fueling the Demands of a Growing Economy (National Petroleum Council, Washington, DC, 2003).
4. Navigant Consulting: North American Natural Gas Supply Assessment (Navigant Consulting, Chicago, IL, 2008).

5. The Potential Gas Committee: Potential Gas Committee Biennial Assessment (Colorado School of Mines, Golden, CO, 2009).

6. Medlock K.B. III: Land of Opportunity: Policy, Constraints and Energy Security in North America (Baker Institute Center for Energy Studies, Rice University, Texas, working paper, 2014).

7. U.S. Energy Information Administration (EIA): Technically Recoverable Shale Oil and Shale Gas Resources: An Assessment of 137 Shale Formations in 41 Countries Outside the United States (Energy Information Administration, Washington, DC, 2013); pp. 2.

8. Bazilian M., Pedersen A., and Baranes E.: Considering shale gas in Europe. Eur. J. Energy 13(1), (2013).

9. Bazilian M., Pedersen A., Pless J., Logan J., Medlock K., O’Sullivan F., and Nakano J.: Shale gas in China: Prospects, concerns, and potential international collaboration. International Shale Gas and Oil Journal 1(1), 36-49 (2013).

10. International Energy Agency: Golden Rules for a Golden Age of Gas: World Energy Outlook (International Energy Agency, Paris, France, 2012).

11. Lechtenbömer S., Altmann M., Capito S., Matra Z., Weindrorf W., and Zittel W.: Impacts of Shale Gas and Shale Oil Extraction on the Environment and on Human Health (European Parliament, Brussels, Belgium, 2011).

12. Wood R., Gilbert P., Sharmina M., Anderson K., Footitt A., Glynn S., and Nicholls F.: Shale Gas: A Provisional Assessment of Climate Change and Environmental Impacts (Tyndall Center, University of Manchester, Manchester, England, 2011).

13. Logan J., Lopez A., Mai T., Davidson C., Bazilian M., and Arent D.: Natural gas scenarios in the U.S. power sector. Energy Econ. 40, 183-195 (2013).

14. Aguilera R.F., Ripple R., and Aguilera R.: Link between endowments, economics, and environment in conventional and unconventional gas reservoirs. Fuel 126, 224 (2014).

15. Pasqualini D. and Bassi A.M.: Oil shale and climate policy in the shift to a low carbon and more resilient economy. Technol. Forecast. Soc. Change 80, 7 (2013).

16. Rivard C., Lavoie D., Lefebvre R., Séjourné S., Lamontagne C., and Duchesne M.: An overview of Canadian shale gas production and environmental concerns. Int. J. Coal Geol. 126, 64-76 (2014).

17. Dooley J.J. and Dahowski R.T.: Large-scale U.S. unconventional fuels production and the role of carbon dioxide capture and storage technologies in reducing their greenhouse gas emissions. Energy Procedia 1(1), 4225-4232 (2009).

18. Verbruggen A. and Al Marchohi M.: Views on peak oil and its relation to climate change policy. Energy Policy 38(10), 5572-5581 (2010).

19. Rahm D.: Regulating hydraulic fracturing in shale gas plays: The case of Texas. Energy Policy 39(5), 2974-2981 (2011).

20. Jacquet J.B.: Landowner attitudes toward natural gas and wind farm development in northern Pennsylvania. Energy Policy 50, 677-688 (2012).

21. McKenzie L.M., Witter R.Z., Newman L.S., and Adgate J.L.: Human health risk assessment of air emissions from development of unconventional natural gas resources. Sci. Total Environ. 424, 79-87 (2012).

22. Stephenson E., Doukas A., and Shaw K.: Greenwashing gas: Might a 'transition fuel' label legitimize carbon-intensive natural gas development? Energy Policy 46, 452-459 (2012).

23. Ward J.D., Mohr S.H., Myers B.R., and Nel W.P.: High estimates of supply constrained emissions scenarios for long-term climate risk assessment. Energy Policy 51, 598-604 (2012).

24. Finkel M.L. and Hays J.: The implications of unconventional drilling for natural gas: A global public health concern. Public Health 127(10), 889-893 (2013).

25. Gross M.: Dash for gas leaves earth to fry. Curr. Biol. 23(20), R901-R904 (2013).

26. Jenner S. and Lamadrid A.J.: Shale gas vs. coal: Policy implications from environmental impact comparisons of shale gas, conventional gas, and coal on air, water, and land in the United States. Energy Policy 53, 442-453 (2013).

27. de Melo-Martín I., Hays J., and Finkel M.L.: The role of ethics in shale gas policies. Sci. Total Environ. 470-471, 1114-1119 (2014). 
28. Wang J., Ryan D., and Anthony E.J.: Reducing the greenhouse gas footprint of shale gas. Energy Policy 39(12), 8196-8199 (2011).

29. Wang Q., Chen X., Jha A.N., and Rogers H.: Natural gas from shale formation-The evolution, evidences and challenges of shale gas revolution in United States. Renewable and Sustainable Energy Rev. 30, 1-28 (2014).

30. Wang C., Wang F., Du H., and Zhang X.: Is China really ready for shale gas revolution-Re-evaluating shale gas challenges. Environ. Sci. Policy 39, 49-55 (2014).

31. Krupnick A., Kopp R.J., Hayes K., and Roeshot S.: The Natural Gas Revolution: Critical Questions for a Sustainable Energy Future (Resources for the Future, Washington, DC, 2014).

32. Arthur J.D., Bohm B., Coughlin B.J., Layne M., and Cornue D.: Evaluating the environmental implications of hydraulic fracturing in shale gas reservoirs. (ALL Consulting, 2008). http://energy.wilkes.edu/PDFFiles/ Issues/EvaluatingTheEnvironmentalImplicationsOfHydraulicFracruring InShaleGasReservoirs.pdf.

33. Zoback M., Kitasei S., and Copithorne B.: Addressing the Environmental Risks from Shale Gas Development (Worldwatch Institute, Washington, DC, 2010).

34. Schmidt C.W.: Blind rush? Shale gas boom proceeds amid human health questions. Environ. Health Perspect. 119(8), a348 (2011).

35. Finkel M.L.: The rush to drill for natural gas: A public health cautionary tale. Am. J. Public Health 101(5), 784-785 (2011).

36. Moniz E.J., Jacoby H.D., Meggs A.J.M., Armstrong R.C., Cohn D.R., Connors S.R., Deutch J.M., Ejaz Q.J., Hezir J.S., Kaufman G.M., Kenderdine M.A., O’Sullivan F., Paltsev S., Parsons J.E., Perez-Arriaga I., Reilly J.M., Seto C., Webster M.D., and Yang Y.: The Future of Natural Gas (Massachusetts Institute of Technology, 2011).

37. Brasier K.J., Filteau M.R., McLaughlin D.K., Jacquet J., Stedman R.C., Kelsey T.W., and Goetz S.J.: Residents' perceptions of community and environmental impacts from development of natural gas in the Marcellus shale: A comparison of Pennsylvania and New York cases. Journal of Rural Social Sciences 26(1), 32-61 (2011).

38. Sakmar S.L.: Shale gas development in North America: An overview of the regulatory and environmental challenges facing the industry. Presented at North American Unconventional Gas Conference and Exhibition, 14-16 June, 2011, The Woodlands, Texas, USA, Society of Petroleum Engineers. http://dx.doi.org/10.2118/144279-MS

39. Bamberger M. and Oswald R.E.: Impacts of gas drilling on human and animal health. New Solutions: A Journal of Environmental and Occupational Health Policy 22(1), 51-77 (2012).

40. Zoback M. and Arent D.J.: Opportunities and challenges of shale gas development. The Bridge 44(1), 16-23 (2014).

41. Suckale J.: Chapter 2-Induced seismicity in hydrocarbon fields. In Advances in Geophysics, Vol. 51, D. Renata, Elsevier: 2009; pp. 55-106.

42. Logan J., Heath G., Paranhos E., Boyd W., Carlson K., and Macknick J.: Natural Gas and the Transformation of the U.S. Energy Sector: Electricity (Joint Institute for Strategic Energy Analysis, Golden, CO, 2012).

43. CNEE: States Seek to Balance Natural Gas Development with Environment and Local Rights Issues (Center for the New Energy Economy, Colorado State University, Fort Collins, CO, 2013).

44. Richardson N., Gottlieb M., Krupnick A., and Wiseman H.: The State of State Shale Gas Regulation (The Energy Institute, University of Texas, Austin, Texas, 2013).

45. Krupnick A. and Kopp R.: Attaining Sustainable Development of Oil and Gas in North America: A Review of the Environmental Regulatory Landscape (Resources for the Future, Washington, DC, 2014).

46. U.S. Bureau of Land Management: Oil and gas hydraulic fracturing on federal and Indian lands. Fed. Regist. 78, 31636 (2013).

47. Exec. Order No. 13605: Supporting safe and responsible development of unconventional natural gas resources. Fed. Regist. 77(74), 23107-23108 (2012).

48. The President's Climate Action Plan (Executive Office of the President, Washington, DC, 2013).

49. Robinson Township v.: Commonwealth of Pennsylvania. 52 A.3d 463 (2012).
50. Brown E., Hartman K., Borick C., Rabe B., and Ivacko T.: Public Opinion on Fracking: Perspectives from Michigan and Pennsylvania. Issues in Energy and Environmental Policy (University of Michigan, 2013).

51. Krupnick A. and Siikamäki J.V.: Would You Pay to Reduce Risks from Shale Gas Development? Public Attitudes in Pennsylvania and Texas (Resources for the Future, Washington, DC, 2014).

52. United States Geological Survey: Groundwater Depletion (2014). http://water.usgs.gov/edu/gwdepletion.html.

53. Horner P., Halldorson B., and Slutz J.: Society for petroleum engineers: SPE 147264 shale gas water treatment value chain-A review of technologies, including case studies. SPE Annu. Tech. Conf. Exhib. 5, 3969-3978 (2011).

54. Vidic R.D., Brantley S.L., Vandenbossche J.M., Yoxtheimer D., and Abad J.D.: Impact of shale gas development on regional water quality. Science 340,6134 (2013).

55. Colorado Oil and Gas Conservation Commission Office of Research and Development: Fact Sheet: Water Sources and Demand for the Hydraulic Fracturing of Oil and Gas Wells in Colorado from 2010 through 2015 (Colorado Oil and Gas Conservation Commission, 2012).

56. Vengosh A., Warner N., Jackson R., and Darrah T.: The effects of shale gas exploration and hydraulic fracturing on the quality of water resources in the United States. Procedia Earth Planet. Sci. 7, 863-866 (2013).

57. Plan to Study the Potential Impacts of Hydraulic Fracturing on Drinking Water Resources. EPA/600/R-11/122 (U.S. Environmental Protection Agency, Washington, DC, 2011).

58. Clark C., Horner R., and Harto C.: Life cycle water consumption for shale gas and conventional natural gas. Environ. Sci. Technol. 47, 11829-11836 (2013).

59. Meldrum J., Nettles-Anderson S., Heath G., and Macknick J.: Life cycle water use for electricity generation: A review and harmonization of literature estimates. Environ. Res. Lett. 8, (2013). doi: 10.1088/ 1748-9326/8/1/015031.

60. Vengosh A., Jackson R.B., Warner N.R., Darrah T.H., and Knodash A.J.: A critical review of the risks to water resources from unconventional shale gas development and hydraulic fracturing in the United States. Environ. Sci. Technol. 48, 8334-8348 (2014).

61. Osborn S.G., Vengosh A., Warner N.R., and Jackson R.B.: Methane contamination of drinking water accompanying gas-well drilling and hydraulic fracturing. Proc. Natl. Acad. Sci. U.S.A. 108(20), 8172-8176 (2011).

62. Jackson R.B., Vengosh A., Carey J.W., Davies R.J., Darrah T.H., O'Sullivan F., and Pétron G.: The environmental costs and benefits of fracking. Annu. Rev. Environ. Resour. 39, 327-362 (2014).

63. Darrah T.H., Vengosh A., Jackson R.B., Warner N.R., and Poreda R.J.: Noble gases identify the mechanisms of fugitive gas contamination in drinking-water wells overlying the Marcellus and Barnett shales. Proc. Natl. Acad. Sci. U.S.A. 111(39), 14076-14081 (2014).

64. Olmstead S.M., Muehlenbachs L.A., Shih J-S., Chu Z., and Krupnick A.J.: Shale gas development impacts on surface water quality in Pennsylvania. Proc. Natl. Acad. Sci. U.S.A. 110(13), 4962-4967 (2013).

65. Secretary of Energy Advisory Board: Shale Gas Production Subcommittee Ninety Day Report (U.S. Department of Energy, Washington, DC, 2011).

66. Secretary of Energy Advisory Board: Shale Gas Production Subcommittee Second Ninety Day Report (U.S. Department of Energy, Washington, DC, 2011).

67. Groat C.G. and Grimshaw T.W.: Fact-based Regulation for Environmental Protection in Shale Gas (Energy Institute, University of Texas at Austin, 2012).

68. Appalachian Shale Recommended Practice Group (ASRPG): Recommended Standards and Practices (2012).

69. Chief Oil and Gas, LLC: Marcellus shale best practices (2012).

70. American Petroleum Institute (API): Water Management Associated with Hydraulic Fracturing, 1st ed. (API Publishing, Washington, DC, 2010).

71. Rahm B.G., Bates J.T., Bertoia L.R., Galford A.E., Yoxtheimer D.A., and Riha S.J.: Wastewater management and Marcellus shale gas development: Trends, drivers, and planning implications. J. Environ. Manage. 120, 105-113 (2013). 
72. U.S. Environmental Protection Agency (EPA): Inventory of U.S. Greenhouse Gas Emissions and Sinks: 1990-2010. EPA 430-R-12-001 (U.S. Environmental Protection Agency, Washington, DC, 2012).

73. Kemp J.: IEA's golden rules for gas are missed opportunity. Reuters Blog. http://blogs.reuters.com/john-kemp/ (2012).

74. Gas industry's first stabs at 'standards' \& 'practices': How much do they reduce accident risk? (Energy Collective, 2012).

75. Pless J.: Natural Gas Development and Hydraulic Fracturing: A Policymaker's Guide (National Conference of State Legislatures, June 2012).

76. Brandt A.R., Heath G.A., Kort E.A., O'Sullivan F., Pétron G., Jordaan S.M., Tans P., Wilcox J., Gopstein A.M., Arent D., Wofsy S., Brown N.J., Bradley R., Stucky G.D., Eardley D., and Harriss R.: Methane leaks from North American natural gas systems. Science 343(6172), 733-735 (2014).

77. Oil and Natural Gas Sector: New source performance standards and national emissions standards for hazardous air pollutants reviews. Fed. Reg. 77(49), 490 (2012).

78. U.S. Environmental Protection Agency (EPA): Overview of Final Amendments to Air Regulations for the Oil and Natural Gas Industry Fact Sheet (U.S. Environmental Protection Agency, Washington, DC, 2012).

79. Control of ozone via ozone precursors and control of hydrocarbons via oil and gas emissions. 5 C.C.R. 1001-9, CO Reg. 7, § XVII-XVIII (2014).

80. Pétron G., Karion A., Sweeney C., Miller B.R., Montzka S.A., Frost G.J., Trainer M., Tans P., Andrews A., Kofler J., Helmig D., Guenther D., Dlugokencky E., Lang P., Newberger T., Wolter S., Hall B., Novelli P., Brewer A., Conley S., Hardesty M., Banta R., White A., Noone D., Wolfe D., and Schnell R.: A new look at methane and non-methane hydrocarbon emissions from oil and natural gas operations in the Colorado DenverJulesburg Basin. J. Geophys. Res. Atmos. 119, 11 (2014).

81. O'Donoughue P., Heath G., Dolan S., and Vorum M.: Life cycle greenhouse gas emissions of electricity generated from conventionally-produced natural gas: Systematic review and harmonization. J. Ind. Ecol. 18(1), 125-144 (2014).

82. Howarth R.W., Santoro R., and Ingraffea A.: Methane and the greenhouse-gas footprint of natural gas from shale formations. Clim. Change $106,679-690$ (2011)

83. Jiang M., Griffin W.M., Hendrickson C., Jaramillo P., VanBriesen J., and Venkatesh A.: Life cycle greenhouse gas emissions of Marcellus shale gas. Environ. Res. Lett. 6, 034014 (2011).

84. Stephenson T., Valle J., and Riera-Palou X.: Modeling the relative GHG emissions of conventional and shale gas production. Environ. Sci. Technol. 45, 10757-10764 (2011).

85. Heath G., O'Donoughue P., Arent D.J., and Bazilian M.: Harmonization of initial estimates of shale gas life cycle greenhouse gas emissions for electric power generation. Proc. Natl. Acad. Sci. U.S.A. 111(31), E3167-E3176 (2014).

86. Brandao M., Heath G., and Cooper J.: What can meta-analyses tell us about the reliability of life cycle assessment for decision support? J. Ind. Ecol. 16(Suppl. 1), S3-S7 (2012).

87. Alvarez R.A., Pacala S.W., Winebrake J.J., Chameides W.L., and Hamburg S.P.: Greater focus needed on methane leakage from natural gas infrastructure. Proc. Natl. Acad. Sci. U.S.A. 109(17), 6435-6440 (2012).

88. Tollefson J.: Methane leaks erode green credentials of natural gas. Nature 493, 12 (2013).

89. Myhre G., Shindell D., Bréon F-M., Collins W., Fuglestvedt J., Huang J., Koch D., Lamarque J-F., Lee D., Mendoza B., Nakajima T., Robock A., Stephens G., Takemura T., and Zhang H.: Anthropogenic and natural radiative forcing. In Climate Change 2013: The Physical Science Basis. Contribution of Working Group I to the Fifth Assessment Report of the Intergovernmental Panel on Climate Change, Stocker T.F., Qin D.,
Plattner G-K., Tignor M., Allen S.K., Boschung J., Nauels A., Xia Y., Bex V., Midgley P.M. eds.; Cambridge University Press: Cambridge, 2013.

90. U.S. Energy Information Administration (EIA): U.S. Energy-Related Carbon Dioxide Emissions (U.S. Department of Energy, Washington, DC, 2012).

91. Pirog R. and Ratner M.: Natural Gas in the U.S. Economy: Opportunities for Growth (Congressional Research Service, R42814, Washington, DC, 2012).

92. U.S. Energy Information Administration (EIA): Natural gas consumption by end use. Annual Energy Outlook 2014 (U.S. Department of Energy, Washington, DC). Accessed online at http://www.eia.gov/forecasts/aeo/ data.cfm?filter=natural_gas\#natural_gas.

93. U.S. Energy Information Administration (EIA): Consumption of fuels used to generate electricity. Electric Power Monthly (September 2014).

94. Broderick J. and Anderson K.: Has U.S. Shale Gas Reduced CO2 Emissions? (Tyndall Manchester Climate Change Research, Manchester, England, 2012).

95. O'Gradey E. and Doggett T.: Duke Sees Danger if U.S. Hooked on Natural Gas (Reuters, Washington, DC, 2011).

96. Rose J.: Waiting for the next polar vortex. Public Utilities Fortnightly (Reston, Virginia, 2014).

97. American Clean Skies Foundation (ACSF): From a bridge to a destination: Gas fired power after 2020. Conf. Proc. (2011).

98. Newell R.G. and Raimi D.: Implications of shale gas development for climate change. Environ. Sci. Technol. 48(15), 8360-8368 (2014).

99. IPCC: Summary for policymakers. Climate change 2014, mitigation of climate change. In Contribution of Working Group III to the Fifth Assessment Report of the Intergovernmental Panel on Climate Change, Edenhofer O., Pichs-Madruga R., Sokona Y., Farahani E., Kadner S., Seyboth K., Adler A., Baum I., Brunner S., Eickemeier P., Kriemann B., Savolainen J., Schlemer S., von Stechow C., Zwickel T., and Minx J.C. eds.; Cambridge University Press: Cambridge, England and New York, NY, USA, 2014.

100. Kirkland J. and Climatewire: Natural gas could serve as 'bridge' fuel to low-carbon future. Sci. Am. (2010).

101. Lopez L.: Study: Natural gas may not be 'bridge fuel' to fight climate change. The Hill (2014).

102. Farrell J.: Natural gas isn't a bridge fuel, It's a gateway drug. Clean Technica (2014).

103. Plummer B.: Obama says fracking can be a 'bridge' to a clean-energy future. It's not that simple. Washington Post (2014).

104. Levi M.: Climate consequences of natural gas as a bridge fuel. CFR. (New York, USA, 2013).

105. Jacoby H. and O'Sullivan F.: The influence of shale gas on U.S. energy and environmental policy. Econ. Energy Environ. Policy 1(1), (2012).

106. Lee A., Zinaman O., Logan J., Bazilian M., Arent D., and Newmark R.: Interactions, complementarities and tensions at the nexus of natural gas and renewable energy. Electricity Journal 25(10), 38-48 (2012).

107. Podesta J.D. and Wirth T.E.: Natural Gas-A Bridge Fuel for the 21st Century (Center for American Progress, Washington, DC, 2009).

108. Energy Modeling Forum: Changing the Game? Emissions and Market Implications of New Natural Gas Supplies, EMF Report 26, Vol. I, 2013.

109. McJeon H., Edmonds J., Bauer N., Clarke L., Fisher B., Flannery B., Hilaire J., Krey V., Marangoni G., Mi R., Riahi K., Rogner H., and Tavoni M.: Limited mitigation of climate change from increased use of globally abundant natural gas. Nature 514, 482-485 (2014).

110. International Energy Agency: Medium-term Coal Market Report (International Energy Agency, Paris, France, 2012).

111. Bazilian M., Brandt A., Billman L., Heath G., Logan J., Mann M., Melaina M., Statwick P., Arent D., and Benson S.: Ensuring benefits from North American shale gas development: Towards a research agenda. Journal of Unconventional Oil and Gas Resources 7, 71-74 (2014). 